\title{
Estigma y empoderamiento posterior al aborto en mujeres mexicanas
}

Post-Abortion Stigma and Empowerment in Mexican Women

Fecha de recepción: 18/09/2021

Fecha de aceptación: 29/11/2021

Fecha de publicación: 07/03/2022

https://doi.org/10.48102/if.2022.v2.n1.212

\author{
Lurel Cedeño Peña* \\ lurelpsi@gmail.com \\ ORCID: https://orcid.org/0000-0002-9674-9942 \\ Doctora en Psicología Social \\ Equidad de Género, Ciudadanía, Trabajo y Familia \\ México
}

\author{
Olivia Tena Guerrero** \\ tena@unam.mx \\ ORCID: https://orcid.org/0000-0002-2758-8233 \\ Doctora en Sociología \\ Universidad Nacional Autónoma de México \\ México
}

\begin{abstract}
* Lurel Cedeño Peña es doctora en Psicología Social por la Universidad Nacional Autónoma de México (UNAM) con la investigación La experiencia narrada del aborto en mujeres mexicanas: entre el estigma y el empoderamiento. Licenciada en Psicología con mención honorífica. Egresada del Diplomado Internacional "El feminismo en América Latina: aportaciones teóricas y vindicaciones políticas", impartido por el Centro de Investigaciones Interdisciplinarias en Ciencias y Humanidades (CEIICH-UNAM). Ha colaborado por más de quince años en organizaciones de la sociedad civil. Es autora del artículo "Guardar/romper el silencio sobre la interrupción voluntaria del embarazo: narrativas de mujeres mexicanas", publicado en la revista Atenea Digital, y coautora del libro Interrupción del embarazo desde la experiencia de las mujeres: aportaciones interdisciplinarias, publicado por el CEIICH-UNAM. Sus líneas de investigación son: género, aborto, embarazo infantil, violencia contra mujeres y niñas, empoderamiento y estigma.

** Olivia Tena Guerrero es licenciada y maestra en Psicología, doctora en Sociología por la UNAM. Adscrita al Centro de Investigaciones Interdisciplinarias en Ciencias y Humanidades de la UNAM, en el Programa de Investigación Feminista. Sus líneas de investigación son: Trabajo, género y salud; estudios feministas sobre la condición masculina y estudios feministas en cor-
\end{abstract}

Cedeño, L. y Tena, O. (2022). Estigma y empoderamiento posterior al aborto en mujeres mexicanas. Iberoforum, Revista de Ciencias Sociales, Nueva Época, 2(1), 1-46, Artículos, e000212. https://doi.https://doi.org/10.48102/if.2022.v2.n1.212 Licencia Pública Internacional - CC BY-NC-ND 4.0 


\section{Resumen}

Este artículo, elaborado desde una perspectiva crítica y feminista, muestra aspectos de la última etapa de la trayectoria del aborto - postabortorelacionados con la salud mental de las mujeres, sus procesos de empoderamiento individual y colectivo, así como el estigma vivido e internalizado; asimismo, desmitifica las experiencias de incomodidad de las mujeres. A partir de esta investigación, encontramos que la mayoría de las mujeres que participaron en el estudio experimentaron tranquilidad después de la interrupción del embarazo. En los pocos casos que no fue así, el malestar temporal se debió a la influencia del discurso conservador que genera miedo y culpa, además de que impide que las mujeres puedan hablar de su experiencia, todo lo cual afecta su bienestar. También observamos procesos de autocuidado, control sobre su propia vida y resistencia de las mujeres a los discursos conservadores, así como intenciones de cuestionar o reafirmar sus deseos de maternidad y construir su futuro poniendo límites a las relaciones violentas. Los procesos de empoderamiento personal y colectivo se entrelazan, por lo que las participantes buscaron que la experiencia del aborto fuera de mayor bienestar y menos estigma para otras mujeres.

\section{Palabras clave}

Estigma, malestar, empoderamiento, postaborto, investigación feminista.

\section{Abstract}

This article, written from a critical and feminist perspective, depicts some aspects of the last stage of abortion-postabortion-in regards to women's mental health, their individual and collective empowerment processes, as well as the lived and internalized stigma; it also demystifies women's experiences of discomfort. From this research, we found that most of the women who participated in the study experienced peace of mind after pregnancy termination. In the few cases where this was not the case, the temporary discomfort was due to the influence of conservative discourse that generates

poraciones policiales. Es investigadora nacional nivel II. Es integrante de la Red Latinoamericana de Investigación y Transferencia de Estudios y Prácticas Sociales de Género en la que ha participado con universidades andaluzas y centroamericanas en análisis de protocolos contra la violencia y actualmente en el desarrollo de un instrumento para el análisis diagnóstico del acoso y hostigamiento sexual en las universidades. Es madre de una periodista feminista y abuela de un pequeño de tres años. 
fear and guilt, in addition to preventing women from being able to talk about their experience, all of which affects their well-being. We also observed processes of self-care, control over their own lives and women's resistance to conservative discourses, as well as intentions to question or reaffirm their desires for motherhood and build their future by placing limits on violent relationships. The processes of personal and collective empowerment are intertwined, which is why the participants sought to make the experience of abortion more comfortable and less stigmatizing for other women.

\section{Keywords}

Stigma, discomfort, empowerment, post-abortion, feminist research.

\section{Introducción}

Este artículo intenta problematizar la patologización de la salud mental de las mujeres después de la interrupción del embarazo; desde una mirada crítica y feminista, toma como ejes de análisis el estigma y el empoderamiento. Además, pretende contribuir a la desmitificación y al análisis crítico de lo que sucede en la vida de las mujeres después de la interrupción del embarazo -última etapa del itinerario abortivo- y evidenciar la influencia de los grupos neoconservadores en el malestar de las mujeres.

Tomamos como punto de partida que, hasta 2018 y posiblemente hasta la actualidad, se mantiene una penalización social además de legal sobre el aborto en la mayor parte del territorio mexicano; sin embargo, al mismo tiempo, ha habido resistencias, rupturas y transgresiones por parte de las mujeres. Esta investigación feminista-narrativa contempla experiencias de mujeres que interrumpieron sus embarazos después de 2007 -año en el que se aprobaron reformas a la Ley de Salud y al Código Penal del entonces Distrito Federal- y hasta 2016 -año en el que las participantes construyeron las narrativas orales y escritas para este estudio-; es decir, esta investigación no retoma los posibles cambios promovidos por la marea verde a partir de 2018.

En el contexto antes descrito, el estigma y el empoderamiento son ejes fundamentales de análisis. El estigma, primer eje, lo entendemos como una expresión del patriarcado, sistema sociopolítico de dominación que, históricamente, ha posicionado la culpa y el mandato de la maternidad a través de discursos en instituciones educativas, legales y 
religiosas, entre otras, para mantener el control sobre el cuerpo de las mujeres y la desigualdad de género (Cedeño, 2020). El estigma como categoría nos permite analizar críticamente la concepción del aborto como algo patológico, ilegal e inmoral, además de ser uno de los principales obstáculos en la trayectoria abortiva que contribuye de manera significativa al malestar de las mujeres (Cedeño, 2020).

También es necesario analizar el rol del estigma en la experiencia posterior a la interrupción -en especial, en su relación con el malestar de las mujeres-, dada la complejidad de estigmas y discriminaciones que experimentan en esta etapa. Debemos recordar que "analizar la relación entre el aborto inducido y la salud de las mujeres es complejo" (Lerner et al., 2016, p. 303), por lo que requiere de un abordaje amplio y multidimensional, sin reduccionismos ni sesgos, con diseños cualitativos o mixtos que den cuenta del contexto situado de las mujeres y de su trayectoria de vida previa y posterior a la interrupción.

Como segundo eje tenemos el empoderamiento de las mujeres, tanto individual como colectivo, sustentado a partir de múltiples investigaciones sobre experiencias de interrupción del embarazo en distintos contextos a nivel nacional, latinoamericano e internacional que señalan que el proceso de interrupción del embarazo puede detonar o se cruza con procesos de autonomía y agencia, de priorizarse a sí mismas (Halldén et al., 2005; Kero et al., 2004; Oduro y Otsin, 2014; Ortiz y Troncoso, 2012; Petracci et al., 2012; Rivas y Amuchástegui, 1997). Es importante aclarar que los procesos de empoderamiento pueden iniciarse incluso antes de la interrupción y que no todas las mujeres viven esta experiencia.

Ortiz (2008) señala que muchas mujeres, después de decidir interrumpir un embarazo, reconocen que "el aborto detonó una crisis que no había sido atendida previamente" (p. 86) y que, para ellas, esta decisión simboliza "una oportunidad para responsabilizarse de sí mismas en los diferentes ámbitos de su vida [...]; especialmente para las jóvenes, el aborto se convierte en la primera elección que las confronta con su capacidad para decidir sobre su vida" (p. 86). Cardich (1993), en un estudio en contextos de penalización, ha afirmado que, para la mayoría de las mujeres que entrevistó, "la experiencia significa una crisis existencial" (p. 20) en la cual ellas reconocen y se hacen responsables de su capacidad reproductiva.

Por otra parte, rechazamos el discurso psicológico que sugiere la existencia del síndrome postaborto; discurso que difunde una serie de fa- 
lacias que prevalecen en el imaginario social. Tomamos como punto de partida la psicología crítica que rechaza el discurso que patologiza la experiencia del aborto, el cual no está basado en evidencia sino en las creencias y sesgos de las y los investigadores, convirtiéndose en una forma de regulación social (Boyle, 1997; Leask, 2014). La psicología no es neutral y "la investigación psicológica también construye el fenómeno en el que se enfoca" (Boyle, 1997, p. 6); no podemos obviar que parte del conocimiento científico se ha utilizado como instrumento para ejercer control sobre la sexualidad y la reproducción de las mujeres (Blázquez, 2008), incluso para regularla legalmente; en el tema del aborto, una de las formas de ejercer dicho control ha sido a través de la patologización de la salud mental de las mujeres que abortan. Por ello, señalamos la importancia de incorporar la perspectiva de género feminista en las investigaciones sobre aborto; investigaciones que complejicen la mirada analizando el contexto, que revisen las ideas y vivencias del o la investigadora del tema y cómo ello impacta en los resultados, y que promuevan el análisis del aborto en relación con temáticas tales como el bienestar, el empoderamiento, la conciencia de género, la ciudadanía y la sobrevaloración de la maternidad.

Incluso en el reporte Task Force on Mental Health and Abortion (American Psychological Association [APA], 2008), se concluyó que el síndrome postaborto no es un diagnóstico válido, que no existe evidencia que lo respalde y que los estudios con metodologías adecuadas "muestran que el estigma, la necesidad de no revelar este hecho y mantenerlo oculto, la exposición a los mensajes antiaborto y la falta de apoyo para tomar la decisión de la interrupción, afectan negativamente la experiencia después de un aborto" (p. 92). ${ }^{1}$ Por otro lado, en el estudio longitudinal Turnaway (Advancing New Standards in Reproductive Health [ANSIRH], 2018), se analizaron los efectos del embarazo no intencionado en la vida de las mujeres, para lo cual se entrevistó y dio seguimiento por cinco años a mil participantes. Al comparar los resultados entre quienes habían tenido acceso a un aborto y a quienes se les había negado, en treinta unidades médicas de Estados Unidos, se identificó que: 1. el aborto no aumentó el riesgo

1 En inglés en el original: "The most methodologically strong studies in this group showed that interpersonal concerns, including feelings of stigma, perceived need for secrecy, exposure to antiabortion picketing, and low perceived or anticipated social support for the abortion decision, negatively affected women's postabortion psychological experiences". 
de depresión, ideación suicida, ansiedad o estrés postraumático ni de consumo de sustancias o alcohol; 2. las mujeres a quienes se les negó el acceso a la interrupción experimentaron más ansiedad y estrés en el momento de la negación y en el corto plazo, además de colocarlas en una mayor inseguridad económica, y 3. antecedentes tales como trastornos mentales, abuso, negligencia y violencia sexual o en la pareja sí se relacionaron con problemas de salud mental postaborto.

Al ser ésta una investigación realizada desde la psicología, y ante la existencia de una serie de mitos sobre la salud mental de las mujeres que abortan, es necesario posicionarse. Tomamos como punto de referencia la reconceptualización que propone Mabel Burín, psicoanalista argentina, en torno al concepto de malestar, particularmente en su libro El malestar de las mujeres: la tranquilidad recetada (Burín et al., 1990). En este texto, plantea las posibles repercusiones en la salud mental de los "modos de vida enfermantes" de las mujeres al estar inmersas en condiciones opresivas de una cultura patriarcal. Propone salir de los dualismos salud-enfermedad y normal-patológico impuestos por el modelo médico hegemónico para pensar en una noción de malestar flexible y transicional que considere las posibilidades y modos de resistencia de las mujeres para enfrentar el malestar, enfatizando su potencial transformador al rechazar los criterios médicos hegemónicos e implementar recursos para los cuidados personales y colectivos. Desde esta concepción, la salud mental deviene en derecho y, al mismo tiempo, en un deber social; tiene un enfoque crítico y se aleja de cualquier objetivo relacionado con la adaptación o la normalización.

$\mathrm{Su}$ modelo tensional-conflictivo propone dos conceptos centrales: conflictos y crisis. Los primeros son situaciones contradictorias e incompatibles que pueden promover la creación de recursos para transformar la tensión; las segundas pueden ser oportunidades propiciadoras de cambio en la salud mental de las mujeres al ser momentos de reconstrucción y deconstrucción. La salud mental de las mujeres, desde esta perspectiva, se asocia con situaciones de conflicto y también con crisis vitales; es decir, tanto con crisis vinculadas con periodos transicionales como con sucesos inesperados que, bajo contextos culturales patriarcales, norman el deber ser de las mujeres. En el caso que nos ocupa, éstos se relacionan con la imposición cultural del deseo o instinto maternal como esencia de la subjetividad femenina y "garante de la salud mental" (Burín et al., 1990, p. 34). Este modelo contribuye a mirar las tensiones y los conflictos como pro- 
piciadores de procesos de transformación y deconstrucción, razón por la cual está siendo retomado por investigadoras feministas como Santarelli y Anzorena (2017), quienes analizan, desde esta perspectiva, las significaciones que construyen las mujeres sobre su experiencia de aborto voluntario medicamentoso en clandestinidad en relación con su salud mental.

En síntesis, este artículo tiene como objetivo analizar, desde una perspectiva feminista crítica y a partir de las categorías de estigma y empoderamiento, la patologización de la salud mental de las mujeres y evidenciar la influencia de los grupos neoconservadores en el malestar de éstas. A continuación presentaremos el diseño metodológico y posteriormente los resultados, divididos en nueve apartados que abordan: las experiencias vitales de las mujeres; el impacto del discurso conservador y del discurso psicológico estigmatizante; el efecto liberador de poder contar su experiencia sin ser juzgadas; la culpa por el embarazo y las estrategias para romper con el estigma. En estas últimas incluimos el acompañamiento, los procesos de empoderamiento personal y colectivo, así como el autocuidado después de la interrupción. Las conclusiones de este artículo contienen líneas de investigación a futuro, los aportes de la metodología y recomendaciones para la política pública.

\section{Diseño metodológico y participantes}

Este artículo toma como punto de partida las teoría e investigación feministas que tienen como finalidad la producción de conocimiento para erradicar la desigualdad de género (Castañeda, 2008), que priorizan y visibilizan la agencia de las participantes de la investigación y que dotan de importancia a la empatía, la relación previa y la confianza, lo cual permite una mayor profundización a partir de entrevistas.

La epistemología feminista del conocimiento situado la articulamos con abordajes narrativos, como una forma de entender y organizar el mundo, incluyendo "la dimensión biográfica, histórica y social" (Martínez y Montenegro, 2014, p. 114), para construir significados y transformar la realidad (Gandarias, 2014). Esta investigación de corte cualitativo da un papel preponderante a la persona que narra, asignándole un rol activo y constructivo. La persona narradora (la mujer que interrumpió un embarazo, en este caso) construye una narración particular, a partir de su posición, circunstancias, punto de vista y subjetividad, también limitada por discursos hegemónicos. Por lo tanto, la narrativa ofrece un abordaje que "desdibuja las dicotomías personal-social y micro-macro" (Martínez y Montenegro, 2014, 
p. 114). El abordaje narrativo da lugar a un sujeto con agencia y creatividad y es una herramienta para la transformación social de la realidad (Martínez y Montenegro, 2014).

Marcela Lagarde (1997) señala que "desde el punto de vista metodológico y desde el punto de vista social, para poder saber cómo se concreta la autonomía de cada mujer tenemos que resumir el método de la biografía" (p. 25); la autora recalca la importancia de la reflexión biográfica y la escritura para la construcción de la autonomía "cuando siempre nos han dicho quiénes somos" (p. 26) o cuando la costumbre es que consultemos a otros. Todo esto también implica hacer genealogía, "resignificar nuestra historia" (p. 26), elaborar lo que estamos pensando y crear alternativas.

El diseño metodológico contempló dos técnicas de investigación, mismas que fueron aplicadas por la doctora Lurel Cedeño Peña en relación directa con las participantes:

1. Narración escrita. Esta técnica permitió dar realce a la propia narrativa de las mujeres y a la forma en la que ellas construyen su experiencia de forma individual, lo que permite la introspección y la reflexión al mirar en retrospectiva. El texto podía escribirse en primera o tercera persona y la extensión fue a elección de cada participante, sin tiempo límite para desarrollar su narración. Esta narración escrita se solicitó antes de la aplicación de la siguiente técnica.

2. Narración oral. Una vez recibida cada narración escrita, se procedió a realizar entrevistas semiestructuradas a cada una de las participantes, con una guía previamente elaborada con base en los objetivos de la investigación, para profundizar en los temas que no hubieran abordado en la narrativa escrita. Las entrevistas tuvieron una duración de 90 a 240 minutos y se realizaron entre septiembre de 2016 y febrero de 2017. Cabe mencionar que dos de las entrevistas se llevaron a cabo de manera virtual por medio de la plataforma Skype debido las dificultades económicas que implicaba el traslado al lugar de residencia de las participantes que se encontraban fuera de la Ciudad de México. Las entrevistas presenciales se realizaron en lugares privados y sin interferencias (cubículos, consultorios o casa de las participantes).

El diseño de la investigación contempló la aplicación de estas técnicas en el orden expuesto debido a que partimos del supuesto de que el habla hacia una misma tiene posibilidades diferentes que el habla dialogada. Teniendo en cuenta que la narración es un proceso de coconstrucción (que en 
este caso comienza con la narración escrita y continúa con la entrevista), en esta última se privilegió un estilo conversacional; se creó un ambiente de confianza en el que las participantes no se sintieran juzgadas.

$\mathrm{Al}$ inicio de la entrevista, a cada participante se le leyó en voz alta un texto informativo en el que se solicitaba su consentimiento informado -el cual fue obtenido y grabado en todos los casos-, mediante el cual autorizaban que la entrevista fuera grabada, declaraban que su participación era voluntaria y reconocían su derecho a interrumpir o cancelar su participación en cualquier momento de la entrevista; también se les informó que ellas podrían revisar la transcripción de las entrevistas y modificar su contenido si lo consideraban necesario, para lo cual se les envió dicho documento vía correo electrónico; algunas participantes no respondieron y otras ratificaron la información o excluyeron segmentos en los que hacían referencia a otras personas. Protegimos la identidad de las mujeres entrevistadas a través del uso de seudónimos, a menos que ellas sugirieran lo contrario; de igual manera, cuidamos la identidad de las personas involucradas en sus relatos.

\section{Participantes}

Participaron catorce mujeres mexicanas elegidas con base en los siguientes criterios de inclusión: 1. que hubieran interrumpido uno o más embarazos antes de las doce semanas de gestación después de 2007, 2. que residieran en México y 3. que tuvieran la disposición de participar de manera voluntaria. Se buscó contactar con una diversidad de mujeres (de distintas edades, niveles educativos y socioeconómicos) con distintas experiencias alrededor de la interrupción del embarazo (diferentes contextos de legalidad, diferente tipo de procedimiento y servicio) (ver tablas 1 y 2 en el anexo).

Sin embargo, la mayoría de las participantes tenían niveles educativos altos, lo cual tuvo que ver con que, aunque se tenía contemplado contactar a las potenciales participantes a través de colectivos $u$ organizaciones feministas, clínicas privadas y Facebook, cuatro estudiantes universitarias solicitaron ser incluidas al conocer la investigación a través de foros y seminarios que organizamos. Dos amigas de la doctora Cedeño participaron por invitación directa; cuatro fueron contactadas por amigas en común; dos más con el apoyo de un proveedor de servicios privados; una a través de una consultora que da acompañamiento después de un aborto seguro, y otra a través de una de las participantes. Cabe resaltar que, al momento de 
la interrupción, nueve de ellas residían en la Ciudad de México, en donde el aborto es legal hasta las doce semanas de gestación, y que las otras cuatro vivían en estados en donde el aborto estaba penalizado.

Algunos elementos para la construcción de confianza fueron nuestra formación profesional, nuestro vínculo con la universidad y nuestra postura respecto al aborto. La construcción de una relación y un espacio de confianza y seguridad para las participantes es fundamental para romper el silencio y el secreto sobre el aborto, lo que posibilita realizar la investigación basada en una posición ética de compromiso (Silva, 2014).

\section{Resultados}

\section{¿Qué pasa en la vida de las mujeres después del aborto?}

A diferencia de los grupos conservadores, que usan el discurso del síndrome postaborto y buscan demostrar una relación causa efecto entre el aborto y la salud mental de las mujeres, nosotras, a partir de esta investigación y en consonancia con un cuerpo sólido de investigaciones (Kero et al., 2004; López, 2015; López y Carril, 2010; Maroto, 2011; Sorhaindo et al., 2014), constatamos que las mujeres que participaron en este estudio experimentaron tranquilidad después de la interrupción; en los pocos casos que no fue así, el malestar fue temporal y se debió a la influencia de dicho discurso conservador.

En etapas previas del itinerario abortivo, las participantes expresaron el ejercicio de sus poderes vitales, germinaron procesos de conciencia de género, mostraron su capacidad de agencia y, en muchos casos, esas acciones de agencia y resistencia se fueron encadenando para formar procesos de empoderamiento tanto personal como colectivo que se mantuvieron después del aborto. En este sentido, Martha Rosenberg (2013) señala que el aborto modifica "los valores dominantes abriendo para las mujeres espacios de posibilidad de nuevas posiciones subjetivas" (p. 104) que cuestionan la maternidad como identidad y mandato para ubicarla como un derecho.

La mayoría de las participantes reafirmaron la decisión de haber interrumpido el embarazo y no se arrepintieron; algunas significaron su interrupción como cambio individual o colectivo y lo integraron a su identidad o vida; su capacidad de agencia se mantuvo presente para buscar apoyo o para rechazar ideas que no contribuían a su tranquilidad; experimentaron cambios en sus vidas en diferentes niveles; reflexionaron sobre su autocuidado; miraron de forma crítica sus prácticas sexuales; hicieron cambios 
en su relación de noviazgo o en el uso de métodos anticonceptivos; a nivel social, modificaron lo que pensaban del aborto o de las mujeres que interrumpen un embarazo, y dejaron de juzgar a otras mujeres.

Sin embargo, en algunos casos, también refirieron malestar emocional por esta decisión, puesto que los miedos y dudas hicieron un engranaje perfecto con el silencio y el estigma en sus diferentes expresiones. En algunos casos, las mujeres narraron momentos difíciles posteriores a la interrupción de sus embarazos, malestares esporádicos y otros más duraderos que, en todos los casos, estaban relacionados con la internalización del estigma y el silencio, mismos que, al momento de la entrevista, habían sido superados.

Si bien estos malestares no se ubicaron en el mismo contexto que el del "malestar que no tiene nombre" de Friedan (1963) ni se expresan como incompletud o insatisfacción, las participantes de esta investigación manifiestan la necesidad (y la dificultad) de construir un "ser para sí", una identidad propia y salir del cautiverio/mandato de la maternidad; al mismo tiempo, la "mística de la feminidad" muestra sus reminiscencias hasta nuestros días, ya que algunas de las participantes aspiraban o aspiran a ser las esposas y madres perfectas, a la par de ser profesionistas o empleadas. La interrupción del embarazo, desde la experiencia de las participantes, puede entenderse como conflicto y crisis vital (Burín et al., 1990) que les permite deconstruir ciertas creencias y mandatos de género y, en algunos casos, construir sus vidas desde otro lugar en el que ellas pueden priorizar sus decisiones y deseos.

Mientras en el proceso decisorio y de acceso al aborto primaba el miedo como emoción, en esta parte de la trayectoria abortiva, la culpa ronda temporalmente a algunas participantes. Desde una mirada feminista, Mizrahi (2003) sostiene que la culpa "es el instrumento más efectivo para neutralizarnos como sujetas autónomas, es un arma de domesticación y sometimiento" (p. 31) ya que anula la subjetividad transformadora.

A continuación, presentamos algunos elementos que contribuyeron a los malestares temporales y al estigma internalizado o experimentado de forma posterior a la interrupción: 1. un discurso conservador ligado a la religión que valida el malestar y el silencio, 2. la idealización de la maternidad, 3. la culpa por el ejercicio de su sexualidad, 4. la ausencia de redes de amistad amplias o fuertes y 5. el espacio doméstico como cautiverio. Aunque la presencia de los hombres vinculados al embarazo es otro elemento importante, no profundizaremos en ello porque su análisis requiere un trabajo detallado.

Cedeño, L. y Tena, O. (2022). Estigma y empoderamiento posterior al aborto en mujeres mexicanas. Iberoforum, Revista de Ciencias Sociales, Nueva Época, 2(1), 1-46, Artículos, e000212. https://doi.https://doi.org/10.48102/if.2022.v2.n1.212 Licencia Pública Internacional - CC BY-NC-ND 4.0 


\section{Discurso conservador y su impacto en la vida}

de las mujeres después de un aborto

En el contexto mexicano, en el que ha coexistido la despenalización, la criminalización y la penalización social, el estigma se hizo presente a lo largo de todo el itinerario abortivo, lo que coincide con los hallazgos de Astbury-Ward et al. (2012), quienes identificaron que las mujeres guardaban el secreto aún en contextos legales debido a la desaprobación que podía generar.

Claro tuve que decir en el trabajo que estaba enferma del estómago y después tuve que conseguir una receta para avalarlo, creo que desde ahí está el estigma con el tema, no es algo que se diga, me parece que se vive desde el silencio y muchas veces en soledad. (Healy, narrativa escrita, noviembre de 2016)

Un punto clave del estigma internalizado parece ser la influencia religiosa en la que ellas crecieron, lo que coincide con los hallazgos de Cockrill y Nack (2013), quienes identificaron que el estigma interno aparece con mayor frecuencia en mujeres en contextos familiares o comunitarios que tienen actitudes negativas hacia el aborto.

Con el paso de los días, me sentí muy mal... ¿ ¿cómo me había atrevido a hacer lo que hice? Dios me castigará, pensaba. ¿Cómo puedes creer que lo que hiciste era lo mejor que podías hacer? ¡Cobarde! Me repetía muchas veces, fue tan difícil... fueron meses que la pasé muy mal, creyendo que no me merecía más que lo peor. (Karla, narrativa escrita, febrero de 2017)

Si la raíz de la culpa es el pecado original de acuerdo con una moral inquisidora, la influencia de la religión en el malestar de las mujeres es evidente; la cacería de brujas, es decir, la persecución de las mujeres que viven su sexualidad fuera de las normas establecidas sigue vigente en múltiples expresiones. Asociado a esto, Amuchástegui et al. (2015) identificaron un mayor apego a los discursos hegemónicos de género y religiosos en las narraciones de mujeres que ya eran madres, vivían o habían vivido en pareja o que se encontraban en relaciones de mayor subordinación, en contraste con las de las mujeres solteras, jóvenes y con mayor autonomía. 
Por ello, es necesario destacar que Karla, Violeta y Lis, tres de las participantes que expresaron mayor malestar en el postaborto, se encontraban en el espacio doméstico, no recibían una remuneración y no tenían redes de amistad amplias o fuertes. Los "modos de vida enfermantes" de los que hablan Burín et al. (1990) también se reflejaron en la experiencia de estas participantes. Las poderosas redes que se entretejen entre religión y espacio doméstico para "nutrir" el malestar y el estigma deben ser visibilizadas y desarticuladas. Cabe mencionar que las participantes que presentaron malestares vivieron el proceso decisorio y de acceso prácticamente en soledad y en silencio, lo que coincide con los hallazgos de Kimport et al. (2011) sobre la falta de apoyo social como uno de los factores que influyen en los efectos psicológicos negativos posteriores al aborto.

A continuación, analizaremos con mayor detalle cuatro casos en los que se presentaron malestares; se hará un recuento de su trayectoria abortiva, la presencia del estigma, el discurso conservador, religioso o científico que permeó su experiencia, y las distintas formas en las que estos malestares se superaron. Los malestares pueden entenderse como la expresión misma de la tensión entre mandatos y deseos que coexisten, a lo que Olivia Tena (2006) denomina "conflicto de deberes".

\section{Sanción social y el poder del afecto para romper el estigma}

Karla vivía con sus papás y se dedicaba al trabajo doméstico no remunerado en un momento de transición entre el término de su carrera profesional y el ingreso al campo laboral; mantenía un noviazgo de muchos años y la expectativa de que si ella quedaba embarazada él iba a hablar con sus papás. Al tomar la decisión, Karla le dio más peso a la posible opinión de sus papás frente a un embarazo fuera del matrimonio y no quiso decepcionarlos o romper la imagen que tienen de ella; la ausencia del deseo de la maternidad no se presentó -como sí ocurrió en otras participantes-y ella sintió que no se dio el tiempo suficiente para pensar. El marco tradicional del ejercicio de la sexualidad apareció cuando la secuencia normativa matrimonio-hijos se rompió; el estigma hacia la sexualidad en soltería reforzó el estigma hacia el aborto.

En su narrativa, ella hizo referencia a sus sentimientos después de la interrupción: 
Sentirte la persona más basura por hacer lo que hiciste, indigna, algunas veces llegué a pensar en que fue el error más grande en mi vida, incluso pensé en que no podía seguir viviendo, ¡vaya! ¿Quién podría vivir con ese peso en sus hombros? (Karla, narrativa escrita, febrero de 2017)

A diferencia de algunas participantes que refirieron que, cuando alguien hacía algún comentario negativo sobre el aborto, ellas detenían el comentario o activamente trataban de rechazarlo, Karla no mostró otras herramientas o la presencia de personas que la ayudaran a oponer resistencia en primera instancia.

Yo escuchaba más todas las cosas que había evitado escuchar, como que era una persona mala y que entonces, toda esa cuestión negativa de alguien que toma esa decisión. Entonces yo ya me creía o me sentí todo eso, que yo era una persona mala como una cuestión de juicio; de por sí somos siempre el verdugo más grande y yo creo que yo fui el verdugo todavía más grande que podía ser. (Karla, narrativa oral, febrero de 2017)

La culpa está bajo una lógica del sacrificio que nos lleva a "postergarnos e inmolarnos" (Mizrahi, 2003, p. 35). En este sentido, es destacable que a Karla nadie le hizo un comentario explícito que detonara la culpa en ese momento; sin embargo, su familia era conservadora. Al incorporar los discursos, nos reprimimos y nos condenamos. La manipulación de las imágenes sobre el desarrollo fetal tomó fuerza en su experiencia y ella nombra al producto como "el bebé". Esto coincide con lo identificado por Gilbert y Sewpaul (2015) sobre el discurso antiderechos que algunas mujeres incorporaron, al nombrarlas pecadoras y asesinas, al hablar en términos de "bebé" o "niño".

Pero estos malestares fueron temporales para Karla. Cuando su novio le pidió matrimonio, algo cambió:

Él me pidió casarnos, y ese día pensé en que, si a pesar de lo que había vivido, él aún quería estar conmigo, eso era símbolo de que él estaba conmigo por amor y no por compasión o no por sentirse culpable o no por lástima. Pensé que era momento de cambiar ese chip de haber 
hecho todo mal, de no merecer nada y no ser feliz jamás en mi vida. Era momento de enfrentar mis acciones, enfrentaría miedos y continuar... (Karla, narrativa escrita, febrero de 2017)

Esta última narrativa nos demuestra los daños a diferentes niveles que el estigma provoca en las mujeres, pues afecta su identidad y la posibilidad de sentirse queridas o amadas; por ello, la petición de matrimonio pudo disolver (por lo menos en parte) sus efectos. Después de la ruptura de este noviazgo y de la cancelación del matrimonio, la psicoterapia y sus amigas jugaron un papel importante para que Karla pensara de forma distinta y reflexionara sobre aspectos políticos y sociales del contexto actual del aborto, pugnando porque otras mujeres lo vivan de forma distinta.

Este tema, que fue muy recurrente y que lo he relacionado con lo malo que he vivido, ha dejado de ser tan fuerte como lo era. Socialmente se cree que quien aborta lo hace por inconsciente... pero al menos, en mi caso, se ha vuelto un continuo cuestionamiento de todo mi sistema de creencias, del sistema tradicionalista social, cultural, político, etc., en el que estamos inmersos... Aunque a partir de ese momento he pensado que se puede construir un sistema más amable, en donde quien decida interrumpir un embarazo no se sienta señalado, juzgado y escondido. (Karla, narrativa escrita, febrero de 2017)

\section{El discurso psicológico estigmatizante y la importancia del apoyo}

Healy, quien fue educada en la religión cristiana e iniciaba una relación de noviazgo, posiblemente estaba influenciada por el discurso religioso en el que ella se crio, del que dice haber escuchado que "se considera que la gente tiene alma a partir de que se concibe", así como por el discurso psicológico del instinto materno esencialista y sin perspectiva de género, a través del cual se obliga a las mujeres a "sentir lo que se debe sentir".

Un buen día me senté y fue a días también, y decía es que mi hijo, como si de verdad se me hubiera muerto un hijo; ahí sí te puedo decir que sentí lo que se debe sentir, no sé si decir afecto, no sé qué otra palabra usar, como ese afecto que dicen que debes sentir por alguien 
que ni has visto ni conoces ni sabes si va a nacer o no. (Healy, narrativa oral, noviembre de 2016)

"Lo que se debe sentir", en palabras de Healy, es el "ideal maternal" constitutivo de la subjetividad femenina del que nos hablan Burín et al. (1990), quienes también señalan que quienes no siguen esta moral maternal son señaladas como mujeres locas e inmorales. Transgredir las normas patriarcales se asocia a la locura.

En los días siguientes a la interrupción, Healy atravesó por momentos de mucha ansiedad que describió de la siguiente forma:

Después comencé a soñar con un hijo (hombre), me levantaba en la madrugada con ataques de ansiedad, llorando y con ganas de salir corriendo a esa hora, mi dije de corazón era mi compañía cada día, leí sobre las consecuencias del aborto (claro, en un tono estigmatizante) lo cual no ayudó, leí que "las parejas se terminan" y eso se tatuó en mi cabeza por mucho tiempo... veía demasiados niños y en ellos veía al que yo no había deseado. (Healy, narrativa escrita, noviembre de 2016)

A diferencia de Karla, Healy no tenía dudas sobre el desarrollo fetal o sobre su decisión; por ello, quizás el conflicto entre no desear y el deber aprendido de desear la maternidad se vio reforzado por el libro que encontró en internet después de la interrupción; sobre esto, ella comentó:

Era un libro que hablaba como de las consecuencias, pero justo estaba como en esa línea... y decía como todas estas cosas, todas eran como negativas, estigmatizadas... Hablaba como de que mucha gente dice que no hay efectos psicológicos, pero sí hay, y que mucha gente se siente con culpa; venían historias de cuando se quisieron embarazar y no pudieron, o que, cuando se embarazaron, tenían miedo que de castigo naciera mal su hijo. (Healy, narrativa oral, noviembre de 2016)

Al preguntarle si la ansiedad había surgido antes o después de leer el libro, Healy se dio cuenta de que fue a partir de la lectura de ese libro; la entrevista le ayudó a escucharse y darse cuenta de ello y así lo expresó: "Ahora que me escucho y lo escucho da la impresión como si yo hubiese 
actuado todos esos efectos psicológicos" (Healy, narrativa oral, noviembre de 2016). Su narrativa nos muestra que los discursos psicológicos que estigmatizan la experiencia y esencializan la maternidad tuvieron cierto eco, al ser ella psicoterapeuta, e impactaron de forma negativa en su experiencia ya que, como señala Blázquez (2008), parte del conocimiento científico se ha utilizado como instrumento de control sobre la sexualidad. Por otro lado, Healy relata que contar en ese momento con apoyo terapéutico afín al reconocimiento de sus derechos contribuyó a su bienestar:

En el proceso terapéutico, yo misma me fui dando cuenta que eso no me estaba ayudando [...] porque era como darle peso a todas las ideas que me generaban mucha angustia, [...] pues es como estar alimentando más la ansiedad. (Healy, narrativa oral, noviembre de 2016)

En este momento de ansiedad, ella sí sintió el apoyo de su pareja; posteriormente, hizo un ritual junto con él, a partir del cual ella se tranquilizó. Al momento de la entrevista, ratificó su decisión.

En esa época tuve una clase sobre los rituales en la terapia y su utilidad, de ahí me vino la idea de deshacerme de mi dije de corazón, como una forma de dejar ir, se lo propuse a mi pareja, le pedí que escribiéramos algo a aquél que no fue nuestro hijo... a partir de entonces se generó en mí una sensación de tranquilidad que en general permanece, estoy cierta y convencida que fue la mejor decisión para mí. (Healy, narrativa escrita, noviembre de 2016)

Como podemos ver, los eventos que les permitieron romper con ese malestar son distintos para Healy y Karla. En el caso de Healy, dada su formación como terapeuta, el ritual le sirvió para cerrar este proceso y pudo hacerlo ella misma. Aunque no es la intención de este trabajo promover los rituales, sí lo es profundizar en las distintas herramientas para enfrentar el estigma internalizado, como acudir a un espacio terapéutico con perspectiva de género, lo que fue de utilidad para varias participantes como Healy y Violeta. 


\section{Violencia, catolicismo y acompañamiento postaborto}

Violeta, quien residía en Guadalajara, tenía dos hijos y vivía con su pareja. Creció bajo una educación católica, se embarazó de su primer hijo siendo adolescente y vivió un proceso complicado en un contexto restrictivo al experimentar la violencia de pareja y no contar con redes de apoyo; mencionó sentirse deprimida al momento del embarazo, incluso con ideación suicida. Aquí cabe recordar que la violencia de pareja, de acuerdo con el estudio Turnaway (ANSIRH, 2018), es uno de los factores asociados con problemas de salud mental postaborto.

Era el momento más depresivo de mi vida, yo sentía ganas de matarme todos los días. Un día me encerré en el baño y dije, ya estaba queriéndome matar, me sentía mal, sin poder hablarlo con nadie por lo mismo que yo no quería que nadie supiera y mi pareja que era el único que sabía, me tachaba de infiel, de mala madre, de floja... yo decía qué hago aquí... (Violeta, narrativa escrita, enero de 2017)

El contexto restrictivo y conservador en el que vivía, el silencio y el aislamiento, así como los discursos religiosos, impactaron en su experiencia. A diferencia de otras participantes que habían manifestado estar a favor del derecho a decidir incluso antes de la experiencia, ella relató lo siguiente:

Ya había dejado de ser católica como lo era antes, pero aun así creía que el aborto era malo y todos esos prejuicios que no solamente te da la Iglesia, sino que te da la gente y tu entorno, el hecho de que cuando en la escuela o algo se habla de abortos todo mundo te voltea a ver y te dicen: "tú no estás a favor, ¿verdad?", te hacen que te metas en la cabeza, está mal. (Violeta, narrativa escrita, enero de 2017)

$\mathrm{Al}$ igual que Karla, Violeta se refería al producto como "bebé" y esperaba un castigo, el cual temía pudiera recaer en sus hijos. Sin embargo, a diferencia de Karla y Healy, fue canalizada por Fondo María para recibir acompañamiento postaborto especializado en ADAS (Acompañamiento Después de un Aborto Seguro). Con este apoyo, Violeta se dio cuenta de las desigualdades en su relación, concretó la ruptura con su pareja, comenzó a estudiar una licenciatura y, al momento de la entrevista, vivía sola; además, dejó de tener miedo al castigo por el aborto. Ella identificó al aborto como 
un parteaguas en su vida, a partir del cual ella puso límites y rompió con el modelo "esposa-madre". Como Ortiz (2008) señala, Violeta pudo resolver una crisis no atendida que el aborto detonó y que representó una oportunidad de responsabilizarse de sí misma.

Y después de eso, no sé, empecé a ver que se abrieron muchas puertas, porque me dieron la ayuda psicológica con Olivia; yo empiezo a ir y me doy cuenta que yo ya no podía seguir con mi pareja; me di cuenta que yo realmente no tenía un apoyo verdadero, tenía apoyo tal vez para las cosas buenas, pero no para las cosas malas... (Violeta, narrativa oral, enero de 2017)

Las primeras sesiones eran llorar, eran siéntate a llorar... Entonces digo, me sirvió mucho dejar atrás el no sentirme culpable, el no culpar a la gente. (Violeta, narrativa escrita, enero de 2017)

Otro aspecto importante es que, después de la interrupción, ella buscó información sobre desarrollo fetal, lo que le permitió romper con el discurso dominante sobre el tema.

Parte de mis terapias, para olvidar y dejar atrás todo esto, fue investigar por qué antes de las ocho semanas y todo eso. Cuando estudié medicina, vi embriología, entonces saqué mi libro y me di cuenta que para empezar el bebé es de este tamaño [haciendo una seña con la mano], aun todavía no tiene desarrollados los nervios, que es una de las cosas con lo que los providas te atacan más: “¿sabes lo que sintió en ese momento?". (Violeta, narrativa oral, enero de 2017)

\section{Momentos de inquietud}

En otros dos casos, se presentaron momentos de inquietud o tensión, activados en ocasiones específicas y ligados al discurso de la vida fetal, aunque, al mismo tiempo, estas participantes ratificaron su interrupción como la decisión correcta. Lis, quien era adolescente al momento del embarazo, acudió años después a una sesión de coaching en el que supuestas autoridades intelectuales reforzaron el estigma, lo que minó su bienestar. Por ello, también es necesario señalar el impacto que personal no calificado pude tener en el bienestar de las mujeres al abordar este tema. 
Tomé un curso de coaching y liderazgo hace cuatro años y salió el tema porque estábamos sacando lo que tenemos en lo profundo y fue cuando empezaron a hablar de los abortos, y casualmente éramos muchas mujeres... y me dijeron: "es que sí tienes algo"; empecé a analizarlo y me di cuenta que sí me dolía, que sí había sido tan insensible. (Lis, narrativa oral, enero de 2017)

Por su parte, María - quien tuvo dudas ya en la clínica, a punto de pasar a que le proporcionaran el medicamento- mostró en su narrativa momentos de tensión entre su agencia y conciencia de derechos y los discursos patriarcales.

Sólo hay momentos en los que sí, siento como estas ideas "asesinaste a un bebé", sí las siento; pero cuando veo películas, hace poco vi una película donde la mujer pierde al bebé y lloran y lloran, te quedas pensando y dices: "iay!, cómo en esos momentos no dudas de tu decisión", pero a veces sí te ganan los prejuicios. Pero llega un momento en el que dices: "no pues, son cosas distintas". (María, narrativa oral, septiembre de 2016)

María definió el aborto de forma ambivalente; para ella este evento no se convirtió en un hito o parteaguas, a diferencia de lo que le ocurrió a otras participantes. El significado que le otorga a su decisión es el de un proceso de larga data que se va construyendo en la vida; un planteamiento como el que hacemos en este estudio.

Todo comenzó hace muchos años, no el aborto, sino lo que me llevó a dicha decisión. Tenemos que entender que el aborto no es un momento que secciona nuestra historia de vida, el aborto es resultado de un proceso de vida colectivo y subjetivo. (María, narrativa escrita, septiembre de 2016)

\section{Sentirse culpable o responsable del embarazo}

Ligado a la culpa y la vergüenza por el embarazo, algunas participantes refirieron sentirse responsables del embarazo durante algún tiempo después de la interrupción. Amuchástegui (2012) planteó que un segundo discur- 
so sobre el control del cuerpo de las mujeres que permea fuertemente el contexto mexicano es el de las políticas de planificación familiar, enfocado a reducir el crecimiento poblacional, "que ha impulsado la noción de elección" (p. 371) y la de "responsabilidad". El uso de estas nociones presenta las decisiones reproductivas como si ocurrieran en el vacío, sin cuestionar el poder en las relaciones de pareja y las dificultades que tienen las mujeres para negociar el uso del condón, lo que obvia otros ejes de opresión y deja a las mujeres como únicas responsables de la reproducción. Este discurso es una razón más para que ellas sientan culpa y malestar.

El contexto legal no modificó estas creencias internalizadas por las mujeres. El duro juicio de irresponsabilidad fue compartido por la mayoría de las entrevistadas. Ésta es otra expresión del estigma internalizado relacionado con el ejercicio de la sexualidad fuera de lo normativo y lo reproductivo.

En el caso de Quetzalli, el miedo, la culpa y el castigo relacionado con la irresponsabilidad se entremezclaron con el temor de un nuevo embarazo. Estos temores estaban vinculados con el discurso de planificación familiar, con las críticas de una amiga y, como hemos mencionado, con el señalamiento de las mujeres que ejercen su sexualidad fuera de lo establecido.

Es que yo creo que sí me quedé con mucha culpa... No culpa de haber querido interrumpirlo, eso no me genera culpa. Más bien, creo que me quedó culpa de haberme embarazado, como que muchos años me quedé pensando: "eres una irresponsable, cómo no te cuidaste, si tenías a la mano condones". Yo siento que sí fue mucho tiempo de juzgarme mucho... (Quetzalli, narrativa oral, octubre de 2016)

La verdad, sí siento que mucho tiempo sí sentía como hasta cierto [pausa] castigo hacia mí misma; después de eso yo creo que tardé como un año en volver a salir con un chavo. Incluso hasta me daba miedo volver a tener relaciones sexuales... Yo ya estaba de "ya no quiero"; me daba miedo mi irresponsabilidad... (Quetzalli, narrativa oral, octubre de 2015)

Este discurso de planificación familiar impactó también a quien usaba un método anticonceptivo al momento del embarazo o que tenía mayor conocimiento sobre el tema. 
Otra cosa que me costó trabajo perdonarme, cómo es posible que yo quedara embarazada, yo que le estoy diciendo a todo mundo "cuídate", yo que estoy haciendo investigación para que la gente no pase por estas cosas, cómo a mí me pasó esto. (Fabiola, narrativa oral, septiembre de 2016)

Algunas participantes relataron que disminuyó su vida sexual y que, en los primeros meses postaborto, se presentó una dificultad para sentir placer, posiblemente asociado al temor a un nuevo embarazo o a la culpa por sentir placer (Rodríguez, 2013), lo que también coincidió con un uso más consistente de métodos anticonceptivos. Tanto en sus palabras como en sus acciones, la idea del castigo, relacionada con la religión judeocristiana, afectó el ejercicio de su sexualidad y su placer.

Porque a partir de ahí nuestra vida sexual disminuyó bastante. Y, de hecho, los últimos tres meses, o sea ha sido casi nada. Al principio, era porque como que te queda cierta sensación, y no puedes disfrutarlo, no puedes disfrutarlo [risas de ella y se da como golpes de látigo en la espalda], y ya después pasa eso y lo disfrutas. (María, narrativa oral, septiembre de 2016)

Mucha gente lo olvida, hasta los doctores lo olvidan, cuándo puedo volver a tener relaciones sexuales, tu vida no acaba, qué sigue, pues puedes en una semana, yo sí lo pregunté. (Andy, narrativa oral, febrero de 2016)

Como contrapeso a este discurso y al sentimiento de culpa, la reflexión sobre la propia experiencia, la formación y el diálogo con las amigas fueron elementos importantes que les hizo replantearse este malestar y considerar el aborto como una práctica común que siempre va a existir, ya sea por una falla en el uso del método anticonceptivo, por la violencia sexual o por la desigualdad de género.

Una amiga asistió a las capacitaciones de Fondo María. Me platicó eso porque ella llegó con ese estigma también. Me di cuenta que no sólo se trata de protegerte y ya, hay muchas mujeres que les pasa, el aborto siempre va a existir, porque estas cosas siempre van a pasar; no va 
a haber un momento en que todos lo vamos a abolir porque todos nos cuidemos, no va a pasar. Y dije: sí. (Quetzalli, narrativa oral, octubre de 2016)

\section{Procesos de empoderamiento personal después de un aborto}

Al mismo tiempo que observamos cómo las participantes estuvieron expuestas a discursos conservadores sobre la sexualidad, la maternidad y el aborto, que les produjeron miedos y culpas, identificamos narrativas de ruptura, trasgresión, conciencia de género y resistencias que van en contra del mandato de la maternidad y del "ser para otros", que respaldan su derecho a decidir. Estos contradiscursos les dieron tranquilidad y les permitieron desplegar diversas formas de resistencia y conciencia política ante la experiencia vivida.

En esta etapa posterior a la interrupción del embarazo, las participantes formularon diferentes significados de la experiencia, que en algunas ocasiones funcionaron como un cierre de la narrativa escrita. Identificamos dos categorías que dan cuenta de estos significados: a) aborto como cambio individual y colectivo; y b) aborto como parte de la identidad o parte de la vida.

Cuando las participantes conceptualizaron el aborto como cambio individual y colectivo, lo situaron como una experiencia de aprendizaje, de darse cuenta de las situaciones en las que se encontraban; una experiencia de cambio para ellas, para otras mujeres o de los límites frente a situaciones de violencia -ya que el embarazo y el futuro hijo implicarían un vínculo permanente con una persona violenta-, lo cual coincide con lo señalado por Ortiz (2008) y Cardich (1993).

Gracias al haberte embarazado pudiste comprender varias situaciones en las cuales te envolviste. (Jimena, narrativa escrita, octubre de 2016)

Qué bueno que no lo tuve, era aguantarlo [a su expareja], ya se empezaba a poner loco. (Lis, narrativa oral, enero de 2017)

Más bien creo que, ehhh... después de haber tomado esta decisión, todo lo que pasó me ayudó a ya no estar en esa relación, no es que hubiera violencia, no había golpes o gritos, creo sí había otras cosas, más sutiles de violencia. (Rosa, narrativa oral, diciembre de 2016) 
Estoy convencida de que saber que existe la opción y que se puede acceder a ella ha cambiado la vida de muchas mujeres, incluyendo la mía y la de mujeres cercanas. (Andrea, narrativa escrita, septiembre de 2016)

Varias participantes narraron cambios importantes en sus vidas a partir de la interrupción. En algunos casos, consiguieron trabajo, terminaron o continuaron sus estudios, viajaron al extranjero; es decir, siguieron su proyecto de vida educativo o profesional y reconocieron la importancia de su independencia económica.

Yo siento que a partir de ese momento cambiaron muchas cosas. Cuando me dieron el resultado final, de ya no estás embarazada, casi a la semana siguiente entré a trabajar y desde ahí no paré de trabajar. Sí termine la escuela, ahorita estoy haciendo mi tesis de licenciatura... porque me di cuenta que sí yo quiero tomar mis propias decisiones; dije "a mí no me vuelve a pasar eso", o no de esa manera tan tajante y traumante en cierto sentido. (Quetzalli, narrativa oral, octubre de 2016)

Creo que la posibilidad de tener un aborto me ha permitido seguir mi vida tranquila, y entonces eso es lo que valoro más y eso digo. Tomé la decisión correcta, de no haber sido así, yo no estaría en la maestría, no estaría viviendo muchas cosas de las que vivo ahorita. (María, narrativa escrita, septiembre de 2016)

Ahora bien, cuando lo conceptualizaron como parte de su vida o de su identidad, ellas identificaron aspectos positivos de esta experiencia y rechazaron estereotipos negativos dirigidos hacia sí mismas; rompieron así el círculo del estigma y el silencio que Kumar et al. (2009) conceptualizaron como paradoja de la prevalencia. Esto posibilitó que compartieran con mayor facilidad sus experiencias con otras mujeres, en sus círculos más cercanos de amistad o de forma más amplia. Los procesos de formación en género o sexualidad que habían tomado en algunos casos, asumir su decisión como un ejercicio de derechos y su capacidad de agencia también contribuyeron a enfrentar el estigma. 
Lo comparto porque es parte de mí, porque fue un momento que me ayuda a crecer, a conocerme, a revisarme y a aceptarme. (Fabiola, narración escrita, septiembre de 2016)

Hasta la fecha yo sigo diciendo "es una experiencia, es parte de mi vida", sobre todo porque yo soy responsable de mis actos; esas cuestiones negativas no fueron parte de mí y no son parte de mí. (Angie, narrativa oral, septiembre de 2016)

En varios momentos he llegado a repensarme y reflexionarme sobre lo que he sido, porque de alguna manera representa algo mío y que es parte de mi vida. (Jimena, narración escrita, octubre de 2016)

Es una etapa que me marcó para toda la vida; que soy quien soy tal vez por eso, tal vez por esa decisión; que tal vez no sería la misma si no hubiera interrumpido el embarazo... (Violeta, narrativa oral, enero de 2017)

Esta experiencia me construyó como una mujer más libre, fortaleció mi relación de pareja, me ha hecho ser más responsable de mi salud. (Healy, narrativa escrita, noviembre de 2016)

Las participantes atravesaron por una serie de circunstancias que obstaculizaron su decisión y su acceso a la interrupción del embarazo, lo que dificultó su experiencia, no por el aborto per se como afirma el discurso que los grupos neoconservadores quieren posicionar.

\section{El efecto liberador de romper el silencio y la importancia del acompañamiento psicológico}

En esta investigación también documentamos algunas experiencias positivas y liberadoras cuando algunas participantes decidieron contar a sus familias, amigas o psicoterapeutas la interrupción del embarazo.

Todo el tiempo que guardé silencio me sentí muy angustiada, y te estoy diciendo que esto no lo revelé hasta apenas hace dos años. Se lo dije a quien me parecía importante que lo supiera... Guardar silencio sobre algo que además yo creía que estaba en lo correcto fue complicado, ¿no? (Andrea, narrativa oral, septiembre de 2016)

Andrea y Fabiola mencionaron que sus relaciones familiares mejoraron y se han fortalecido a partir de contarles sobre la interrupción. Ellas se 
sintieron comprendidas, amadas, apoyadas y aceptadas. Fabiola percibió de una forma diferente a su familia, menos apegada a las normas sociales, y ratificó su decisión cuando lo contó.

Pasaron años antes de que me atreviera a hablarlo con mi familia. La respuesta fue completamente distinta a lo que pensé que sería, estuvo llena de amor y comprensión y yo estoy bien. (Andrea, narrativa escrita, septiembre de 2016)

Cuando quieres a la persona, todas esas normas y los deber ser se acaban; mientras la persona que quieres esté bien, la apoyas. Me siento apoyada por mi familia y no es un tema tabú en mi familia. (Fabiola, narrativa oral, septiembre de 2016)

Sin embargo, al momento de contar esta experiencia, la narrativa de Fabiola también nos muestra los miedos a la pérdida de afectos y al rechazo familiar relacionado con el estigma que prevalecía.

Cuando veo cómo se le descompone la cara, sentí horrible porque mi miedo era que me dejaran de querer... que esto fuera un momento que marcara nuestra relación, que a partir de este momento dijeran "ya no eres nuestra hija, no aprobamos tu estilo de vida". (Fabiola, narrativa oral, septiembre de 2016)

Karla esperaba recibir un castigo y el juicio de sus amigas (una de ellas tiene formación terapéutica), pero sucedió todo lo contrario: sus amigas identificaron el estigma interno que ella sentía, no la juzgaron y la ayudaron a observar su propio juicio y reducirlo. Cabe mencionar que Karla fue la única que mencionó la palabra "verdugo", que nos remite a una narrativa medieval de tortura.

Una de ellas pues nada, comprendía, siempre ha sido una persona que me apoya, no me apoya ciegamente... Yo creo que el tema era un tema muy sensible; me decía: "de por sí tú eres tu verdugo más fuerte como para que haya alguien más"; era como quitarle un poquito esa carga negativa que yo le estaba poniendo y ella como que la quitaba. En el otro caso, mi otra amiga es cristiana, yo ahí me esperaba hasta el juicio final y no al contrario... (Karla, narrativa oral, febrero de 2017) 
Contar con un espacio terapéutico fue de gran ayuda para resistir al estigma y poder romper el silencio en el ámbito familiar.

Por supuesto que me vio mi psicóloga, llevo como un año, a ella le hablé desde que me pasó; la verdad es que un apoyo impresionante; es una señora como de sesenta años, súper abierta, diciéndome: "yo te entiendo, voy a hablar con una amiga que se dedica a esto"; sentí mucho apoyo de su parte. (Andy, narrativa oral, febrero de 2017)

Yo sabía que en diciembre iba a hablar con ellos, yo sabía perfecto que no iba a dejar pasar el año sin que hablara con ellos, porque me sentía hipócrita. Y me lo hizo ver mi psicólogo: "si lo estás haciendo porque tú lo quieres hacer, adelante; pero si lo haces como un confesionario, como que sientes que les estás mintiendo a tus papás, no manches". (Fabiola, narrativa oral, septiembre de 2016)

Angie señaló la importancia de la información y de contar con personas cercanas que respalden tu decisión para romper con los mitos sobre el síndrome postaborto:

Muchas personas dicen, bueno, la mujer, es un proceso difícil, porque puedes tener complicaciones psicológicas o emocionales, eso tiene que ver mucho con las creencias que tú traes y con la educación, y sin embargo si las personas que están a tu lado te apoyan, pues igual y sí tienes esa dificultad o hay necesidad de que lo hables, pero no creo que todas tengamos que pasar por ese proceso. (Angie, narrativa oral, septiembre de 2016)

Esta necesidad de apoyo emocional ha sido atendida en Estados Unidos a través de líneas telefónicas como Exhale, con mujeres voluntarias que mantienen un espacio para hablar después de la interrupción del embarazo (Kimport et al., 2011). En México, esta necesidad no ha sido atendida totalmente, ya que dentro de los servicios públicos o privados no se ofrece este tipo de atención. Por ello, impulsar el modelo de ADAS (liderado por Olivia Ortiz) y el trabajo de colectivas estatales que proporcionan acompañamiento en la trayectoria abortiva es fundamental.

En este mismo sentido, la formación con perspectiva de género para dar acompañamiento es fundamental para los psicólogos y psicólogas que 
ejercen en el sector privado y público; de esta forma, pueden canalizar o atender a mujeres en cualquier momento del itinerario abortivo y sin objeción de conciencia, ya sea que apoyen el proceso decisorio, de acceso o la atención de su bienestar emocional posterior a la interrupción.

\section{Autocuidado}

El autocuidado y el empoderamiento son procesos que están estrechamente vinculados. En algunos casos, las participantes hicieron patente que, a partir de la interrupción del embarazo, tuvieron un mayor contacto con su cuerpo; señalaron un diálogo constante, una reconexión o mayor conciencia. También mencionaron que ahora tienen más cuidado con su cuerpo, lo que se vincula en algunos casos al ejercicio de su vida sexual.

Inclusive, a partir de ahí, comencé a revisarme más, a esta salud sexual, de papanicolau; eso creo que da pauta a que te cuides. (Angie, narrativa oral, septiembre de 2016)

Hoy, después de ocho meses me recuerdo constantemente el dialogar con mi cuerpo, no volverme a olvidar de él, de cuidarlo y poner atención a sus cambios con los que se comunica conmigo. (Fabiola, narrativa escrita, septiembre de 2016)

Ahora tengo más cuidado, finalmente es mi cuerpo y esta experiencia me ha hecho pensar mucho, si no lo cuido, no sólo en la lógica de represión por aspectos morales, sino porque realmente el cuerpo no es sólo un objeto que me da placer, no habrá tenido sentido. (María, narración escrita, septiembre de 2016)

Estos hallazgos coinciden con los de Ortiz y Troncoso (2012), así como con los de Sorhaindo et al. (2014); en este último estudio, se documentó que las mujeres menores de treinta años señalaron que, en cierto sentido, el aborto había tenido una consecuencia positiva, pues las hacía mirar hacia ellas mismas.

Incluso Andy, quien tenía la experiencia más reciente de todas las participantes (un mes) y trabajaba en el área de salud, nos mostró la importancia de reflexionar sobre esta experiencia y sobre su propio autocuidado; para ella, el cuidado hacia los demás es algo cotidiano por su profesión, aunque no ubica este "ser para otros" como desigualdad de género sino como un rasgo de personalidad. Tal vez, para algunas participantes, la ex- 
periencia de la interrupción es uno de los primeros momentos en los que se priorizaron a sí mismas.

Me vino una lección muy fuerte, puedes saberlo, qué tanto me cuido yo; yo normalmente me descuido muchísimo, siempre pongo muchas cosas antes que a mí y a mi salud, porque pienso que no me va a pasar nada a mí, pero ya vi que sí; de repente fue como una lección... de cuidarme y de pensar que no tengo que cuidar a todos los demás nada más... de repente me doy cuenta que yo nunca me volteo a ver. (Andy, narrativa oral, febrero de 2017)

Algunas participantes también reflexionaron y tomaron una posición crítica sobre el ejercicio de su sexualidad y su responsabilidad en cómo ocurrió el embarazo, ya que no estaban usando métodos anticonceptivos o sólo utilizaban métodos naturales para prevenirlo. Esta reflexión las llevó a la acción para realizar ciertos cambios: por ejemplo, en la relación de pareja que detallamos más adelante o en el uso de métodos anticonceptivos, lo que ha sido también identificado en mujeres españolas (Rodríguez, 2013) y suecas (Kero et al., 2004). Sin embargo, prevalece cierta narrativa de culpa. A partir de la interrupción, la mayoría utilizó métodos anticonceptivos, algunas de largo plazo y otras de corto plazo; sólo una de las participantes, al momento de la entrevista, no estaba usando métodos anticonceptivos porque quería embarazarse.

\section{Construyendo sus destinos}

Ligado a este autocuidado, varias participantes relacionaron la experiencia de la interrupción con un mayor control sobre sus vidas y sus cuerpos, así como con cambios que les permiten mayor autonomía. Frente a una decisión trascendental con implicaciones de por vida como lo es la continuación o la interrupción del embarazo y ante la disyuntiva de seguir los mandatos o construir su destino, ellas reafirmaron el rumbo que quieren para sus vidas: construir su destino. Este mayor control sobre sus vidas se ubica dentro de un proceso de empoderamiento, como lo señalamos en la introducción.

A veces voy caminando por la calle y pienso: "estos pasos que estoy dando son míos, yo puedo estar caminando a esta hora, en este día, 
en esta calle, porque yo lo decidí y no porque la vida me trajo aquí". Sí siento que me he apropiado de mi vida. (Fabiola, narrativa oral, septiembre de 2016)

Soy Healy, me gusta mi vida como es, he aprendido y sigo aprendiendo a estar y ser consciente de mí, de mis emociones, de mis decisiones, sin dejarle a nada ni a nadie la responsabilidad sobre mi destino; poco a poco he conquistado espacios de libertad en donde tengo la certeza de que es mi derecho elegir la forma en la que quiero vivir. (Healy, narrativa oral, noviembre de 2016)

Andy y Angie relacionaron esta experiencia con poner límites a las personas y ser adultas e independientes en todos los ámbitos, como lo señala Ortiz (2008). Con estas reflexiones, Andy dio continuidad a un proceso de empoderamiento que había iniciado un año antes cuando terminó una relación de pareja.

Pero me doy cuenta que a veces tengo que tomar decisiones por mí y primero veo a todas las demás para ver si no afecto a nadie con eso; a veces, aunque se afecte al de al lado, si tú no quieres, no quieres; eso me pasa mucho en mi relación pasada y en esta relación con este chavo. (Andy, narrativa oral, febrero de 2017)

Karla, después de la ruptura del compromiso de matrimonio con la pareja que tenía al momento del embarazo, mostró su valía como persona independientemente de su condición de soltería y reivindicó su rebeldía.

Yo siempre he sido una persona, mi papá antes decía que yo era muy rebelde; yo decía: "no digas que soy rebelde", yo lo tomaba a mal, porque yo lo pensaba como tal. La palabra rebelde pues sí es fuerte, como algo en negativo; ahora lo veo y digo: "sí soy rebelde porque cuestiono, soy consciente de tantas cosas que nos tratan de imponer". (Karla, narrativa oral, febrero de 2017)

El cuestionamiento sobre la maternidad continuó en algunas de las participantes; éste apunta hacia una maternidad deseada, voluntaria y en mejores condiciones económicas, así como de salud; también criticaron el 
mandato de la maternidad expresado a través de distintos discursos y prácticas que restringen sus elecciones.

En el caso de Fabiola, la presión familiar por su maternidad la motivó a hablar sobre su interrupción con su familia, aunque también expresó el temor de perder sus afectos como consecuencia de no cumplir el mandato de la maternidad.

"Yo sé que para ti es muy importante la maternidad y no te estoy diciendo que no quiero ser mamá, solamente que ahorita no, y no quiero y no quiero". Le conté todo, y mi hermana lloró y yo también lloré y le dije: "mi miedo es que me dejes de querer porque yo sé que para ti tu vida gira en torno a la maternidad". (Fabiola, narrativa oral, septiembre de 2016)

Fabiola reafirmó su identidad y su valía como persona, independientemente de su calidad de madre o esposa, mientras que Rosa mostró una transformación en sus expectativas sobre la maternidad: la elección se privilegió ante el "reloj biológico".

Antes del embarazo, yo les decía a mis compañeras de la universidad que quería tener un hijo o hija a los veintiocho años; era como una meta o un plan. Pero ya después... era pensar si me ponía otro plazo, cuántos años y, más bien, últimamente digo que no sé; en parte sí me gustaría, a veces no; más bien no es algo que me preocupe tanto. Hubo un tiempo en que lo pensaba por la edad... ya después dije: "no, si en algún momento me decido a que sí, cuando sea, y si fuera ya después de que pueda embarazarme yo, pues buscar otras opciones"; en eso ha cambiado porque ya no me siento, no es como algo que tenga que decidir ya. (Rosa, narrativa oral, diciembre de 2016)

En el mismo tenor, de dejar abierta la posibilidad de la no maternidad, Healy mencionó que ha platicado con su pareja y reconoció la presión familiar. La narrativa de Healy y Rosa difieren de lo encontrado por Amuchástegui (2012) después de la despenalización del aborto en la Ciudad de México: las participantes de su estudio no cuestionaron su maternidad como proyecto; sólo era posible retrasarla, pero no evitarla. Healy no quiere arriesgar su proyecto de vida y su identidad por el ejercicio de la ma- 
ternidad, que restringiría de forma importante sus tiempos, aunado a una enfermedad de su pareja.

Creo que otra [transgresión] va a ser - porque es algo que hemos estado dialogando mucho mi pareja y yo, y que tiene que ver con esto, que creo que va a ser muy fuerte, y que yo siento mucha presión en mi familia- no ser madre... Mi terapeuta me decía: "Si yo te preguntara en este momento si quieres ser mamá..."; yo dije: "no, a mí me gusta mi vida como es, amo trabajar todo el día"... Pero yo amo lo que hago, yo, si me sacas de esos ambientes, es como perder mi identidad, como transgredir mi identidad... Yo no quiero ser una madre sola y sé que no hay garantía de nada, igual y yo me muero primero, pero también sé que mi esposo... puede que un día no esté. (Healy, narrativa oral, noviembre de 2016)

La vida en pareja como requisito para la maternidad fue una idea expresada por Andy, quien se cuestionó si logrará encontrar una pareja igualitaria; consideró factible la monomarentalidad en un futuro, aunque no es la opción deseada. El ideal de la maternidad (Burín et al., 1990) aparece con fuerza en la narrativa de Andy.

Me sigo respondiendo que, aunque sea mamá soltera, me gustaría ser mamá; por eso trabajo mucho... Como que trato de estar preparada, aunque por supuesto que no me gustaría, y claro que creo que un hombre tiene que estar bien presente ahí también, tú no puedes hacer todo, aunque la mujer es maravilla también se cansa; eso es lo que pienso. (Andy, narrativa oral, febrero de 2017)

Tanto a Healy como a Andy les preocupa tener a su cargo todo el cuidado y la responsabilidad económica de un hijo o una hija. Ante la enfermedad de su pareja, Healy prácticamente descarta la posibilidad de la maternidad; mientras que Andy trata de prepararse para ello y cuenta con mayores recursos económicos para efectuarlo. En cambio, Rosa se ha planteado ser madre soltera, tal vez debido a las experiencias de su mamá y su abuela, quienes vivieron violencia con sus parejas. 
Siempre he tenido la idea de no casarme; mi idea era tener un hijo o una hija pero yo sola, pero no casarme. Soy la única prima de la familia materna que no tiene hijos ni se ha casado. (Rosa, narrativa oral, diciembre de 2016)

La presión de ser "buenas madres" y "supermujeres" que puedan cumplir miles de roles con eficacia y perfección también está presente en sus narrativas. ¿Los hombres también se plantean esto?

A diferencia de otras participantes, al momento de la entrevista, María y Angie manifestaron que estaban planeando embarazarse en el corto plazo ya que sentían que estaban en otro momento de sus vidas y continuaban con las mismas parejas con las que salían cuando interrumpieron el embarazo - a pesar de haber enfrentado reclamos o de identificar distancia y desigualdad en la experiencia de la interrupción-.

Ahorita sí queremos tener, ya lo estamos planificando; yo sé a lo mejor que la planificación no te puede servir, porque te vas a dar clases a no sé dónde o no encuentras trabajo; ahorita sí ya es una idea de "en tal fecha te embarazarías" y construir algo juntos, y tenerlo. (María, narrativa oral, septiembre de 2016)

\section{Poniendo límites en sus relaciones de pareja}

A partir de la interrupción, varias participantes comenzaron procesos de rechazo ante la violencia experimentada en sus relaciones de pareja; el primer paso fue la identificación de situaciones de desigualdad y de reproducción de relaciones patriarcales. Esto coincide con lo señalado por Ortiz y Troncoso (2012) y Guevara (2005), quienes indican que, para las mujeres, el aborto significó la posibilidad de poner límites en una relación en la que ellas están en desventaja.

En algunos casos, las participantes exigieron y lograron cambios en su vida sexual y reproductiva, especialmente en lo que se refiere al uso de anticonceptivos, terreno de mayor responsabilidad e inversión económica por parte de las mujeres.

Hasta que un día le dije: "oye, pues es que tú, cabrón, muy fácil para ti, ¿no?, tú también fuiste parte de la decisión, pero quien está sufriendo todas las consecuencias ahorita soy yo y me puse el implante porque 
sé que tú eres un huevón, porque no vas a comprar los condones porque eres bien codo"... Le dije: "me vas a acompañar al ginecólogo, vas a investigar conmigo y me vas a cooperar", y sí, en ese momento le cayó el veinte. (María, narrativa oral, septiembre de 2016)

En el caso de María, estas reflexiones fueron detonadas por la participación en una clase con Marta Lamas; es decir, el discurso feminista tuvo cierta influencia y pudo catalizar cambios.

Y acababa yo de estar en una clase, no sé si era, ¡ahhh, sí!, con Marta Lamas de hecho, en donde dije: "oye, sí es cierto, estamos reproduciendo ciertas relaciones patriarcales", porque efectivamente yo estoy sufriéndolo sola, no lo estoy compartiendo con él, y fue cuando dije: "ya, no es justo, en serio no es justo, yo sé que no vas a sentir lo que siento, pero sé empático". (María, narrativa oral, septiembre de 2016)

Una situación similar fue narrada por Angie, quien se priorizó a sí misma y rechazó el reclamo de su pareja por haber abortado; él pasaba "factura a su compañera ante sus propios conflictos morales" (Guevara, 2005, p. 43).

Cuando se presentaba alguna discusión, fueron dos ocasiones, él lo sacaba a relucir, "es que tú"; en la segunda ocasión, yo le dije: "sabes que no, yo te dije que lo iba a hacer, no ahora me vengas con que yo tengo la culpa, porque para empezar ni siento culpa ni siquiera eso va a ser una manipulación para que yo me sienta mal". (Angie, narrativa oral, septiembre de 2016)

De ahí en las discusiones ya no salía el tema, yo ya no le preguntaba “¿cómo te sientes?", porque en ese momento yo decía "soy más importante yo, lo que yo siento y lo que yo quiero". (Angie, narrativa oral, septiembre de 2016)

Dice Guevara (2005) que "La relación amorosa es un espacio sui géneris para el ejercicio de poder" (p. 39). Tal vez una de las participantes adquirió conciencia de ello a partir de la experiencia de interrupción pues, 
después de terminar con sus vínculos erótico afectivos, buscó un compañero con el cual establecer relaciones distintas:

También sí influyó en que fuera más selectiva, después del desencanto del chavo con el que me embaracé, sí me hice más selectiva. Mi pareja actual, no digo que sea el mejor hombre del mundo, pero al menos es un hombre que me convence, es chido, es interesante, siento que vale la pena. (Quetzalli, narrativa oral, octubre de 2016)

\section{De lo personal a lo político y viceversa}

La mayoría de las participantes continuaron o iniciaron el proceso de tomar conciencia de las desigualdades y dificultades que viven las mujeres, así como de las diferentes expresiones del patriarcado, y mostraron interés en el tema del aborto. Desde distintos frentes, algunas participantes trataron de contribuir a hacer un cambio para otras mujeres, lo que también representa una transformación en sus propias vidas. Sin empoderamiento colectivo, no hay empoderamiento personal, ya que, si pensamos que el derecho al aborto sólo se justifica para una y no para todas, seguiremos jugando del lado del patriarcado. En el caso de Quetzalli, había acudido a foros y cursos sobre aborto; incluso su investigación de tesis gira en torno a este tema.

Como yo no había estado en esa circunstancia como que no estaba al pie del cañón informándome. Después de que me pasó, ahora sí, es un tema al que le pongo atención... Realmente han sido varios años de irlo reflexionando, hasta la vez que fui con ustedes al foro, pensaba en todo ese proceso mío desde mi experiencia. (Quetzalli, narrativa oral, octubre de 2016)

Para Rosa, el ingreso a una organización como promotora el mismo año de la interrupción significó un cambio importante en su vida y detonó otros cambios como el fortalecimiento de sus redes de amistad, un mayor conocimiento del feminismo y una participación ciudadana más activa.

Ese mismo año, en agosto de ese año, vi una convocatoria de la organización para entrar como promotora, pues bueno a partir de ahí sí 
hubo como cambios; retomé el trabajo que tenía que ver con temas de género y sexualidad; a partir de ahí empecé a tener relación con personas que ahorita son importantes y meterme más en esto de ser activista. (Rosa, narrativa oral, diciembre de 2016)

A la par de romper el silencio como postura política, las participantes dieron otras muestras de sororidad hacia las mujeres que estaban viviendo esta experiencia: las acompañaron, las asesoraron sobre el aborto seguro o estaban dispuestas a acompañar a alguna mujer si fuese necesario.

Fabiola, quien vivió una experiencia privilegiada al contar con el apoyo de sus amistades, acompañó a otras mujeres en la interrupción de sus embarazos, rompiendo de esta forma con el planteamiento de otros estudios que señalan que el aborto sólo es justificado para sí pero no para las demás. Fabiola dio muestras de sororidad y ciudadanía sexual y reproductiva.

La verdad es que los abortos siempre han existido y seguirán existiendo. En mi idealismo sólo espero que más de una mujer tenga la oportunidad de vivirlo como lo viví yo, en la comodidad de mi casa, con linda compañía, amor, comprensión y mucho aprendizaje. (Fabiola, narrativa escrita, septiembre de 2016)

Rosa también dio acompañamiento dentro de la organización en la que participó y cuenta lo que les dijo a las mujeres:

Yo les digo que son ellas las que conocen su situación, que es su decisión; puede ser algo que no pensaban hacer antes, que, si en ese momento es lo mejor para ellas, es su decisión y tratarles de hacer sentir que cualquier duda que tengan para eso estoy yo ahí, para ayudarles a resolver. (Rosa, narrativa oral, diciembre de 2016)

Andrea y Lis estaban dispuestas a dar acompañamiento, en un futuro, a otras mujeres durante todo el proceso, sin juicios ni presiones:

Si yo tuviera una amiga, la acompañaría en todo el procedimiento, justamente porque tengo la experiencia de que no es fácil, porque no es tu escenario ideal. (Andrea, narrativa oral, septiembre de 2016) 
Así como lo hizo Iris conmigo, así, de llevarlas, acompañarlas, estar en el proceso, de no pasa esto, pasa esto, yo creo que es la mejor manera en que puedes apoyar a alguien, ni diciéndole sí o si no. (Lis, narrativa oral, enero de 2017)

Ligado a la conciencia de género y a la sororidad, otro cambio que habían experimentado la mayoría de las participantes fue su reflexión y, en consecuencia, la disminución de las críticas que hacían hacia otras mujeres, en especial por su comportamiento sexual. Ahora se mostraban más empáticas, por lo que la idea de la inmunidad se cae:

Cuando veía a niñas o jóvenes de mi edad que se embarazaban, yo era mucho de juzgarlas; decía "uy, esta mensa ya se fue a meter y habiendo métodos anticonceptivos, y tanta cosa e información"; lo primero que hacía era el juicio... Cuando me tocó a mí, dije: "cállate la boca porque no sabes cuándo puedes estar en esa situación”. (Lis, narrativa oral, enero de 2017)

\section{Conclusiones}

No debemos olvidar que el largo proceso de expropiación de la autonomía que hemos vivido las mujeres respecto de nuestra capacidad reproductiva y nuestra sexualidad es y ha sido clave para la dominación y explotación patriarcal, capitalista y colonial (Ciriza, 2013). Tan es así que, ante cualquier avance en la despenalización legal y social del aborto que pone en "crisis" esta dominación, se presentan reacciones conservadoras que nos han implicado retrocesos. Por ello, las narrativas de las mujeres mexicanas que interrumpen un embarazo muestran tensiones entre la búsqueda de su autonomía y un contexto estigmatizante y de culpa que las acecha. Sin duda, la marea verde ha generado una mayor despenalización social; posiblemente ha hecho pensable el aborto para muchas mujeres que atraviesan por un embarazo no intencionado, tal como la despenalización del aborto lo hizo para algunas mujeres que vivían en el Distrito Federal (ahora CDMX). Las recientes sentencias de la Suprema Corte de Justicia de la Nación -que impiden que las mujeres de todo el país sean criminalizadas por abortar y que sientan precedente para que los congresos locales lo despenalicenson un gran avance; sin embargo, la despenalización del aborto legal y so- 
cial, la calidad de los servicios y el acceso al aborto seguro - no sólo en términos médicos sino psicológicos- serán cuestiones de especial atención en el futuro inmediato; un futuro que muestra cifras alarmantes de violencia sexual y feminicida.

Desde la investigación y el activismo feministas seguiremos generando propuestas para deconstruir el mandato de la maternidad, así como el estigma hacia la sexualidad y el aborto; seguiremos abonando en la construcción de la autonomía, la sororidad y el empoderamiento de las mujeres, evidenciando los mecanismos sutiles y visibles del patriarcado y los cruces con otros ejes de opresión que dificultan la experiencia. Esto es de suma importancia para todas las mujeres, particularmente para aquéllas que atravesaron experiencias de estigma e interrupción del embarazo, como las aquí narradas, y que participan en el activismo por los derechos de las mujeres.

Para algunas participantes que crecieron bajo una fuerte influencia religiosa, que se encontraban en el espacio doméstico y que vivieron la interrupción del embarazo aisladas o en silencio, que no habían tenido rupturas o transgresiones previas al embarazo, enfrentar y resistir al estigma después de la interrupción fue más difícil; la presencia de discursos psicológicos que validan el síndrome postaborto o la ausencia de diálogo con sus parejas contribuyeron también al malestar. Sin embargo, los malestares fueron temporales: disminuyeron y desaparecieron cuando ellas enfrentaron el estigma. Cabe resaltar que no se observaron diferencias en el malestar de las mujeres según su lugar de residencia (Ciudad de México y otros estados); tal vez esto se deba a sus niveles educativos y la cercanía, en algunos casos, con el discurso feminista.

Al identificar el estigma, emergieron formas de resistencia a éste. Aunque todas lo percibieron, algunas participantes evitaron internalizarlo cuando: 1. se dieron cuenta de que emociones como la culpa son un potente mecanismo de control y están basadas en creencias externas a ellas; 2. buscaron información (por ejemplo, sobre desarrollo fetal) que les permitió contraargumentar; 3. comenzaron a hablar de su experiencia y se dieron cuenta de que no eran las únicas; 4. contaron con el apoyo y validación de sus redes sociales, lo que les permitió sentir o pensar que la interrupción de un embarazo no afectaba sus afectos o su identidad, y 5. recibieron apoyo psicológico especializado -como en ADAS- que les permitió ver el aborto como una experiencia de crecimiento. Cuando las 
mujeres identificamos los mecanismos neoconservadores, nos revelamos, resistimos y rechazamos seguir manteniendo el statu quo.

Las participantes mostraron su capacidad de agencia; las redes de apoyo, el acompañamiento y el discurso feminista, así como la legalidad y la gratuidad se tornaron fundamentales para su bienestar. Ellas reconocen el camino tradicional (el matrimonio y los hijos), pero algunas han decidido un camino alterno: construir su propio camino, a su propio ritmo, cuestionando el mandato de la maternidad y el instinto materno que les han enseñado no sólo en su familia sino incluso en los espacios universitarios. Al interrumpir un embarazo es posible que las mujeres comiencen a "adueñarse de un cuerpo que jamás fue suyo" (Basaglia, 1986, p. 122) y que no termina de ser suyo; es decir, la apropiación del cuerpo en este contexto capitalista patriarcal presenta siempre tensiones, contradicciones y ambigüedades.

La metodología utilizada en esta investigación resulta no sólo apropiada, sino impulsora de cambios y reflexiones en la vida de las participantes. Esperamos que, a partir de esta investigación, esta metodología pueda ser utilizada desde el activismo y la investigación feminista, que se generen nuevas líneas de investigación que analicen las tensiones discursivas y las trayectorias abortivas de mujeres ante la presencia de la marea verde y la reciente despenalización del aborto en Hidalgo, Coahuila, Veracruz, Baja California y Oaxaca. También sería importante evaluar el impacto de la pandemia por COVID-19 y el confinamiento, que posiblemente está provocando una reducción del apoyo social y una menor presencia de redes, importantes para el bienestar, como lo hemos señalado.

Desde el modelo de salud de Burín et al. (1990), la salud mental es un derecho. En nuestro país, falta recorrer un trecho importante para asegurar el bienestar de las mujeres que atraviesan el itinerario abortivo; por ello, desde el movimiento feminista, no descansaremos hasta lograrlo.

\section{Referencias bibliográficas}

Advancing New Standards in Reproductive Health (2018, mayo). Estudio Turnaway: El impacto de obtener o de ser negado un aborto deseado sobre la salud mental de la mujer [resumen informativo]. http://

www.redaas.org.ar/archivos-recursos/442Mental\%20Health\%20 Issue\%20Brief_Spanish.pdf

American Psychological Association (2008). Report of the APA Task Force on Mental Health and Abortion. APA. 
Amuchástegui, A. (2012). La experiencia del aborto en tres actos: cuerpo sexual, cuerpo fértil y cuerpo del aborto. En R. Parrini (ed.), Los archivos del cuerpo, ¿Cómo estudiar al cuerpo?, (pp. 367-392). Universidad Nacional Autónoma de México.

Amuchástegui, A., Flores, E. y Aldaz, E. (2015). Disputa social y disputa subjetiva. Religión, género y discursos sociales en la legalización del aborto en México. Revista de Estudios de Género. La Ventana, 5(41), 153-195.

Astbury-Ward, E., Parry, O. y Carnwell, R. (2012). Stigma, abortion and disclosure. Findings from a qualitative study. Journal of Sexual Medicine, 9(12), 3137-3147.

Basaglia, F. (1986). Mujer: el cuerpo como prisión. Cuadernos de Marcha, $3^{\text {ra }}$ Época, 2(8), 69-76.

Blázquez, N. (2008). El retorno de las brujas: Incorporación, aportaciones y críticas de las mujeres en la ciencia. Universidad Nacional Autónoma de México, Centro de Investigaciones Interdisciplinarias en Ciencias y Humanidades.

Boyle, M. (1997). Rethinking abortion: Psychology, gender, power, and law. Routledge.

Burín, M., Moncarz, E. y Velázquez, S. (1990). El malestar de las mujeres: La tranquilidad recetada. Paidós.

Cardich, R. (1993). Desde las mujeres, visiones del aborto: Nexos entre sexualidad, anticoncepción y aborto. Movimiento Manuela Ramos.

Castañeda, M. (2008). Metodología de la investigación feminista. Centro de Investigaciones Interdisciplinarias en Ciencia y Humanidades, Universidad Nacional Autónoma de México, Fundación Guatemala.

Cedeño, L. (2020). La experiencia narrada del aborto en mujeres mexicanas: Entre el estigma y el empoderamiento. Facultad de Psicología, Universidad Nacional Autónoma de México.

Ciriza, A. (2013). Sobre el carácter político de la disputa por el derecho al aborto. 30 años de luchas por el derecho a abortar en Argentina. En C. Anzorena y R. Zurbriggen (eds.), El aborto como derecho de las mujeres: Otra historia es posible (pp. 17-38). Herramienta.

Cockrill, K. y Nack, A. (2013). "I'm not that type of person": Managing the stigma of having an abortion. Deviant Behavior, 34(12), 973-990.

Friedan, B. (1963). The Feminine Mystique. Norton \& Company.

Gandarias, I. (2014). Tensiones y distensiones en torno a las relaciones de poder en investigaciones feministas con Producciones Narrativas. Quaderns 
de Psicologia. International Journal of Psychology, 16(1), 127-140.

Gilbert, I. y Sewpaul, V. (2015). Challenging dominant discourses on abortion from a radical feminist standpoint. Affilia, 30(1), 83-95. http:// doi.org/10.1177/0886109914549232

Guevara, E. (2005). La corresponsabilidad ética de los varones frente al aborto. Desacatos, (17), 33-56.

Halldén, B. M., Christensson, K. y Olsson, P. (2009). Early abortion as narrated by young Swedish women. Scandinavian Journal of Caring Sciences, 23(2), 243-250.

Kero, A., Högberg, U. y Lalos, A. (2004). Wellbeing and mental growth-longterm effects of legal abortion. Social Science $\mathcal{E}$ Medicine, 58(12), 2559-2569.

Kimport, K., Foster, K. y Weitz, T. (2011). Social sources of women's emotional difficulty after abortion: Lessons from women's abortion narratives. Perspectives on Sexual and Reproductive Health, 43(2), 103-109. http:// doi.org/10.1363/4310311

Kimport, K., Perucci, A. y Weitz, T. (2011). Addressing the silence in the noise: How abortion support talklines meet some women's needs for non-political discussion of their experiences. Women $\mathcal{E}$ Health, 52(1), 88-100.

Kumar, A., Hessini, L. y Mitchell, E. (2009). Conceptualising abortion stigma. Culture, Health \& Sexuality, 11(6), 625-639. http://doi. org/10.1080/13691050902842741

Lagarde, M. (1997). Para mis socias de la vida. Claves feministas para el poderío y la autonomía de las mujeres, los liderazgos entrañables y las negociaciones en el amor. Horas y Horas.

Leask, M. (2014). Constructing women as mentally troubled: The political and performative effects of psychological studies on abortion and mental health. Women's Studies Journal, 28(1), 74-82.

Lerner, S., Gillaume, A. y Melgar, L. (2016). Realidades y falacias en torno al aborto: Salud y derechos humanos. El Colegio de México, Centro de Estudios Demográficos, Urbanos y Ambientales; Institute de Researche pour le Développement.

López, A. (2015). Mujeres y aborto. El papel de las condiciones legales y sociales en las trayectorias y experiencias subjetivas de las mujeres frente al aborto inducido. En S. Ramos (ed.), Investigación sobre aborto en América Latina y El Caribe: Una agenda renovada para 
informar políticas públicas e incidencia (pp. 19-38). Consorcio Latinoamericano contra el Aborto Inseguro, Centro de Estudios de Estado y Sociedad, Centro de Promoción y Defensa de los Derechos Sexuales y Reproductivos, Population Council. http://clacaidigital. info/handle/123456789/661

López, A. y Carril, E. (2010). Aborto voluntario y subjetividad en contextos de penalización. Efectos y significados en mujeres, varones y profesionales de la salud. Psicología, Conocimiento y Sociedad, 1(02), 1-32.

Maroto, A. (2011). Al amparo de la noche: Abortos clandestinos y salud mental. Revista Costarricense de Psicología, 29(44), 65-75.

Martínez, A. y Montenegro, M. (2014). La producción de narrativas como herramienta de investigación y acción sobre el dispositivo de sexo/ género: Construyendo nuevos relatos. Quaderns de Psicologia, 16(1), 111-125. http://doi.org/10.5565/rev/qpsicologia.1206

Mizrahi, L. (2003). Las mujeres y la culpa. Herederas de una moral inquisidora. Nuevohacer. Grupo Editor Latinoamericano.

Oduro, G. Y. y Otsin, M. N. A. (2014). "Abortion-It is my own body": Women's narratives about influences on their abortion decisions in Ghana. Health Care for Women International, 35(7-9), 918-936.

Ortiz, O. (2008). Un acercamiento al aborto legal en México: La experiencia de las mujeres. En G. Freyermuth y E. Troncoso (eds.), El aborto: Acciones médica y estrategias sociales (pp. 81-87). Comité Promotor por una Maternidad sin Riesgos, Ipas México A. C.

Ortiz, O. y Troncoso, E. (2012). El aborto voluntario como experiencia saludable en mujeres de la Ciudad de México. V Congreso de la Asociación Latinoamericana de Población, Montevideo, Uruguay.

Petracci, M., Pecheny, M., Mattioli, M. y Capriati, A. (2012). El aborto en las trayectorias de mujeres y varones de la ciudad de Buenos Aires. Sexualidad, Saludy Sociedad - Revista Latinoamericana, 0(12), 164-197.

Rivas, M. y Amuchástegui, A. (1997). Voces e historias sobre el aborto. Edamex. Rodríguez, R. (2013). Itinerarios corporales de aborto en mujeres argentinas y españolas. En C. Anzorena y R. Zurbriggen (eds.), El aborto como derecho de las mujeres: Otra historia es posible (pp. 263-282). Herramienta.

Rosenberg, M. (2013), ¿Quiénes son esas mujeres? En C. Anzorena y R. Zurbriggen (eds.), El aborto como derecho de las mujeres: Otra historia es posible (pp. 17-38). Herramienta.

Santarelli, M. y Anzorena, C. (2017). Los socorrismos y las disputas de 
sentidos sobre el aborto voluntario: Consideraciones teóricas desde una perspectiva del feminismo crítico. Descentrada. Revista interdisciplinaria de feminismos y género, 1(1), e008.

Silva, P. (2014). Experiências de abortos provocados de mulheres e homens de estratos sociais médios no nordeste brasileiro. Instituto de Saúde Colectiva, Universidade Federal da Bahia.

Sorhaindo, A., Juárez-Ramírez, C., Olavarrieta, C., Aldaz, E., Piñeros, M. y García, S. (2014). Qualitative evidence on abortion stigma from Mexico City and five states in Mexico. Women \& Health, 54(7), 622-640.

Tena, O. (2006). Los malestares subjetivos de las mujeres académicas como un conflicto de deberes. En M. Favela Gavia y J. Muñoz Rubio (coords.), Jornadas Anuales de Investigación 2005. Centro de Investigaciones Interdisciplinarias en Ciencias y Humanidades, Universidad Nacional Autónoma de México. 


\section{Anexo}

Tabla 1. Características de las participantes ${ }^{2}$

\begin{tabular}{|c|c|c|c|c|c|c|c|c|}
\hline $\begin{array}{c}\text { Partici- } \\
\text { pante }\end{array}$ & $\begin{array}{c}\text { Edad al } \\
\text { momen- } \\
\text { to de la } \\
\text { entre- } \\
\text { vista }\end{array}$ & $\begin{array}{c}\text { Lugar } \\
\text { de resi- } \\
\text { dencia al } \\
\text { momento } \\
\text { de la } \\
\text { entrevista }\end{array}$ & $\begin{array}{l}\text { Otros } \\
\text { lugares de } \\
\text { residencia }\end{array}$ & $\begin{array}{l}\text { Escola- } \\
\text { ridad al } \\
\text { momento } \\
\text { de la en- } \\
\text { trevista }\end{array}$ & $\begin{array}{l}\text { Ocupación } \\
\text { al mo- } \\
\text { mento de } \\
\text { la entre- } \\
\text { vista }\end{array}$ & $\begin{array}{l}\text { Ocupación } \\
\text { al momen- } \\
\text { to de la } \\
\text { interrup- } \\
\text { ción }\end{array}$ & $\begin{array}{l}\text { Año de } \\
\text { la inte- } \\
\text { rrupción }\end{array}$ & Religión \\
\hline Fabiola & 29 & $\begin{array}{l}\text { Ciudad de } \\
\text { México }\end{array}$ & $\begin{array}{l}\text { Nayarit y } \\
\text { Monterrey }\end{array}$ & $\begin{array}{l}\text { Posgrado } \\
\text { en curso }\end{array}$ & Estudiante & $\begin{array}{c}\text { Misma } \\
\text { ocupación }\end{array}$ & 2014 & $\begin{array}{l}\text { Sin re- } \\
\text { ligión } \\
\text { (familia } \\
\text { católica) }\end{array}$ \\
\hline María & 30 & $\begin{array}{l}\text { Ciudad de } \\
\text { México }\end{array}$ & & $\begin{array}{l}\text { Posgrado } \\
\text { en curso }\end{array}$ & Estudiante & $\begin{array}{c}\text { Desem- } \\
\text { pleada/ } \\
\text { TDNR }^{3}\end{array}$ & 2015 & $\begin{array}{l}\text { Sin re- } \\
\text { ligión } \\
\text { (familia } \\
\text { católica) }\end{array}$ \\
\hline Angie & 27 & $\begin{array}{l}\text { Ciudad de } \\
\text { México }\end{array}$ & & $\begin{array}{l}\text { Licencia- } \\
\text { tura }\end{array}$ & $\begin{array}{l}\text { Funciona- } \\
\text { ria pública }\end{array}$ & Estudiante & 2013 & $\begin{array}{l}\text { Sin re- } \\
\text { ligión } \\
\text { (familia } \\
\text { católica) }\end{array}$ \\
\hline Andrea & 32 & $\begin{array}{l}\text { Ciudad de } \\
\text { México }\end{array}$ & & Maestría & $\begin{array}{l}\text { Colabo- } \\
\text { radora en } \\
\text { ONG }\end{array}$ & $\begin{array}{c}\text { Desem- } \\
\text { pleada/ } \\
\text { TDNR }\end{array}$ & 2012 & $\begin{array}{l}\text { Sin re- } \\
\text { ligión } \\
\text { (familia } \\
\text { católica) }\end{array}$ \\
\hline Jimena & 26 & $\begin{array}{l}\text { Ciudad de } \\
\text { México }\end{array}$ & & $\begin{array}{l}\text { Licencia- } \\
\text { tura }\end{array}$ & $\begin{array}{l}\text { Profesio- } \\
\text { nista }\end{array}$ & Estudiante & $\begin{array}{c}2009 y \\
2015\end{array}$ & $\begin{array}{l}\text { Sin re- } \\
\text { ligión } \\
\text { (familia } \\
\text { católica) }\end{array}$ \\
\hline Quetzalli & 29 & $\begin{array}{l}\text { Estado de } \\
\text { México }\end{array}$ & & $\begin{array}{l}\text { Licencia- } \\
\text { tura }\end{array}$ & Docente & Estudiante & 2011 & $\begin{array}{l}\text { Sin re- } \\
\text { ligión } \\
\text { (familia } \\
\text { católica) }\end{array}$ \\
\hline Healy & 33 & $\begin{array}{l}\text { Ciudad de } \\
\text { México }\end{array}$ & $\begin{array}{l}\text { Estado de } \\
\text { México }\end{array}$ & Maestría & Docente & $\begin{array}{l}\text { Estudiante } \\
\text { y docente }\end{array}$ & 2014 & $\begin{array}{l}\text { Sin re- } \\
\text { ligión } \\
\text { (familia } \\
\text { cristiana) }\end{array}$ \\
\hline Dany & 24 & Querétaro & $\begin{array}{c}\text { Municipio } \\
\text { Guana- } \\
\text { juato }\end{array}$ & $\begin{array}{l}\text { Licencia- } \\
\text { tura en } \\
\text { curso }\end{array}$ & $\begin{array}{l}\text { Psicóloga } \\
\text { y promo- } \\
\text { tora }\end{array}$ & Estudiante & 2012 & $\begin{array}{l}\text { Sin re- } \\
\text { ligión } \\
\text { (familia } \\
\text { católica) }\end{array}$ \\
\hline Rosa & 34 & Querétaro & $\begin{array}{l}\text { Municipio } \\
\text { Guana- } \\
\text { juato }\end{array}$ & $\begin{array}{l}\text { Licencia- } \\
\text { tura }\end{array}$ & $\begin{array}{l}\text { Docente y } \\
\text { promotora }\end{array}$ & Empleada & 2011 & $\begin{array}{l}\text { Sin re- } \\
\text { ligión } \\
\text { (familia } \\
\text { católica) }\end{array}$ \\
\hline
\end{tabular}

2 A cada participante se le leyó en voz alta un texto informativo en el que se solicitaba su consentimiento informado para participar voluntariamente en la investigación, el cual fue obtenido y grabado en todos los casos; protegí su identidad y la de sus personas cercanas a través del uso de seudónimos, a menos de que ellas sugirieran lo contrario.

3 Trabajo doméstico no remunerado.

Cedeño, L. y Tena, O. (2022). Estigma y empoderamiento posterior al aborto en mujeres mexicanas. Iberoforum, Revista de Ciencias Sociales, Nueva Época, 2(1), 1-46, Artículos, e000212. https://doi.https://doi.org/10.48102/if.2022.v2.n1.212

Licencia Pública Internacional - CC BY-NC-ND 4.0 


\begin{tabular}{|c|c|c|c|c|c|c|c|c|}
\hline Andy & 26 & $\begin{array}{l}\text { Ciudad de } \\
\text { México }\end{array}$ & Canadá & $\begin{array}{l}\text { Licencia- } \\
\text { tura }\end{array}$ & $\begin{array}{c}\text { Cargo } \\
\text { directivo }\end{array}$ & $\begin{array}{c}\text { Misma } \\
\text { ocupación } \\
\text { actual }\end{array}$ & 2017 & Católica \\
\hline Lis & 26 & $\begin{array}{l}\text { Ciudad de } \\
\text { México }\end{array}$ & & $\begin{array}{l}\text { Prepa- } \\
\text { ratoria } \\
\text { trunca }\end{array}$ & Empleada & TDNR & 2008 & $\begin{array}{l}\text { Sin re- } \\
\text { ligión } \\
\text { (familia } \\
\text { católica) }\end{array}$ \\
\hline Violeta & 26 & $\begin{array}{l}\text { Guadala- } \\
\text { jara }\end{array}$ & $\begin{array}{l}\text { Varios } \\
\text { estados }\end{array}$ & $\begin{array}{l}\text { Licencia- } \\
\text { tura en } \\
\text { curso }\end{array}$ & Estudiante & $\begin{array}{c}\text { Trabajo } \\
\text { doméstico } \\
\text { no remu- } \\
\text { nerado }\end{array}$ & 2014 & Católica \\
\hline Paulina & 23 & Chiapas & $\begin{array}{l}\text { Municipio } \\
\text { rural de } \\
\text { Oaxaca }\end{array}$ & $\begin{array}{l}\text { Licencia- } \\
\text { tura en } \\
\text { curso }\end{array}$ & Estudiante & $\begin{array}{c}\text { Estudiante } \\
\text { de bachi- } \\
\text { llerato }\end{array}$ & 2013 & Católica \\
\hline Karla & 34 & $\begin{array}{l}\text { Ciudad de } \\
\text { México }\end{array}$ & & $\begin{array}{l}\text { Posgrado } \\
\text { en curso }\end{array}$ & Estudiante & TDNR & 2010 & Católica \\
\hline
\end{tabular}

Tabla 2. Características de la interrupción

\begin{tabular}{|c|c|c|c|c|}
\hline Participante & Procedimiento & Tipo de servicio ${ }^{4}$ & Redes de apoyo & $\begin{array}{c}\text { Año de la } \\
\text { interrupción }\end{array}$ \\
\hline Fabiola & Medicamentos & Privado & $\begin{array}{c}\text { Amigas, amigos y } \\
\text { pareja }\end{array}$ & 2014 \\
\hline María & Medicamentos & $\begin{array}{l}\text { Clínica de Salud } \\
\text { Sexual } \\
\text { Reproductiva } \\
\text { SEDESA }\end{array}$ & Amigas y novio & 2015 \\
\hline Angie & Medicamentos & $\begin{array}{l}\text { Clínica de Salud } \\
\text { Sexual } \\
\text { Reproductiva } \\
\text { SEDESA }\end{array}$ & Amigas y novio & 2013 \\
\hline Andrea & AMEU & Privado & $\begin{array}{c}\text { Amiga (apoyo lo- } \\
\text { gístico) }\end{array}$ & 2012 \\
\hline Jimena & $\begin{array}{l}\text { 1. AMEU } \\
\text { 2. Medicamentos }\end{array}$ & $\begin{array}{l}\text { 1. Privado } \\
\text { 2. Clínica de Salud } \\
\text { Sexual } \\
\text { Reproductiva } \\
\text { SEDESA }\end{array}$ & $\begin{array}{c}\text { 1. Papás y amiga } \\
\text { 2. Novio }\end{array}$ & $\begin{array}{l}\text { 1. } 2009 \\
\text { 2. } 2015\end{array}$ \\
\hline Quetzalli & Espontáneo & Privado & Amiga & 2011 \\
\hline
\end{tabular}

4 Registramos en esta columna el servicio al que finalmente las mujeres accedieron para la interrupción; sin embargo, varias participantes acudieron antes a otros servicios públicos o privados.

5 Los novios o parejas no tuvieron un rol de apoyo en todos los casos, incluso llegaron a obstaculizar el acceso o a afectar el bienestar de las participantes; por ello se omiten en algunas ocasiones en esta columna.

Cedeño, L. y Tena, O. (2022). Estigma y empoderamiento posterior al aborto en mujeres mexicanas. Iberoforum, Revista de Ciencias Sociales, Nueva Época, 2(1), 1-46, Artículos, e000212. https://doi.https://doi.org/10.48102/if.2022.v2.n1.212

Licencia Pública Internacional - CC BY-NC-ND 4.0 


\begin{tabular}{|c|c|c|c|c|}
\hline Healy & AMEU & Privado & $\begin{array}{c}\text { Novio y compañeras } \\
\text { de trabajo }\end{array}$ & 2014 \\
\hline Dany & AMEU & $\begin{array}{l}\text { Clínica de Salud } \\
\text { Sexual } \\
\text { Reproductiva } \\
\text { SEDESA }\end{array}$ & ONG & 2012 \\
\hline Rosa & AMEU & Privado & ONG & 2011 \\
\hline Andy & Medicamentos & Privado & Amigas y pareja & 2017 \\
\hline Lis & Medicamentos & Consultorio privado & Amiga & 2008 \\
\hline Violeta & AMEU & SEDESA & ONG & 2014 \\
\hline Paulina & Medicamentos & Privado (en Chiapas) & Amiga & 2013 \\
\hline Karla & AMEU & Privado & & 2010 \\
\hline
\end{tabular}

